\title{
Response Priming with More or Less Biological Movements as Primes
}

\author{
David Eckert ${ }^{1}$ - Christina Bermeitinger ${ }^{1,2}$
}

Published online: 5 May 2016

(C) The Psychonomic Society, Inc. 2016

\begin{abstract}
Response priming in general is a suitable tool in cognitive psychology to investigate motor preactivations. Typically, compatibility effects reflect faster reactions in cases in which prime and target suggest the same response (i.e., compatible trials) compared with cases in which prime and target suggest opposite responses (i.e., incompatible trials). With moving dots that were horizontally aligned, Bermeitinger (2013) found a stable pattern of results: with short SOAs, faster responses in compatible trials were found; with longer SOAs up to $250 \mathrm{~ms}$, faster responses in incompatible trials were found. It is unclear whether these results are specific to the special motion used therein or whether it generalizes to other motions. We therefore used other motions realized by arrangements of dots. In four experiments, we tested point-light displays (biological coherent walkers vs. less biological scrambled/split displays) as primes. In two experiments, eye gaze motions realized by moving dots representing irises and pupils (i.e., biological) versus the same motion either without surrounding face information or integrated in an abstract line drawing (i.e., less biological) were used. We found overall large positive compatibility effects with biological motion primes and also positive - but smaller - compatibility effects with less biological motion primes. Most important, also with very long SOAs (up to $1320 \mathrm{~ms}$ ), we did not
\end{abstract}

David Eckert and Christina Bermeitinger contributed equally to this work.

Christina Bermeitinger

bermeitinger@uni-hildesheim.de

1 Institute for Psychology, University of Hildesheim, Hildesheim, Germany

2 Department of Psychology, University of Hildesheim, Universitaetsplatz 1, D - 31141 Hildesheim, Germany find evidence for negative compatibility effects. Thus, the pattern of positive-followed-by-negative-compatibility effects found in Bermeitinger (2013) seems to be specific to the materials used therein, whereas response priming in general seems an applicable tool to study motion perception.

Keywords Response priming $\cdot$ Movement $\cdot$ Motion perception · Priming · Point-light walker · Gaze perception . Biological movement

\section{Introduction}

There are various kinds of motion surrounding us in our daily life. Perception and discrimination of different kinds of motion represent an important ability, already present in newborns (Farroni, Massaccesi, Pividori, Simion, \& Johnson, 2004; Simion, Regolin, \& Bulf, 2008). Indeed, the special role of motion and moving objects in perception and attention has garnered much interest among researchers (Bosbach, Prinz, \& Kerzel, 2004, 2005; Egeth \& Yantis, 1997; O'Craven, Rosen, Kwong, Treisman, \& Savoy, 1997; Treue \& Maunsell, 1996). Furthermore, it is an old suggestion that perception is directly linked to action (James, 1890). In cognitive psychology, this suggestion is the key point of the theory of event coding (Hommel, Müsseler, Aschersleben, \& Prinz, 2001; see also van der Wel, Sebanz, \& Knoblich, 2013): perception of action and performance of action is coded in a common representational code. In turn, observing actions or motions activates the same motor programs involved in performing that same action (Jeannerod, 1994; Prinz, 1997) and a close connection is assumed between action observation and production (CalvoMerino, Glaser, Grèzes, Passingham, \& Haggard, 2005; Cross, Kraemer, de C. Hamilton, Kelley, \& Grafton, 2009; Decety \& Grèzes, 1999; Di Pellegrino, Fadiga, Fogassi, 
Gallese, \& Rizzolatti, 1992; Grèzes, Fonlupt, Bertenthal, Delon-Martin, Segebarth, \& Decety, 2001; Kilner, Paulignan, \& Blakemore, 2003; Saygin, Wilson, Hagler, Bates, \& Sereno, 2004). In embodied views, there is the general claim that "perception is for action" (Chemero, 2006; Gibson, 1979; Warren, 2006). The discovery of mirror neurons provided a neurological basis for these findings and suggestions (Rizzolatti et al., 1996).

\section{Response Priming and Moving Prime Stimuli}

Recently, Bermeitinger (2013) introduced a motion variant of response priming in which moving dot rows were used as primes (henceforth "row-of-dots primes") for static arrow targets (for other response priming variants with motion primes, see Mattler \& Fendrich, 2007; Sarkheil, Vuong, Bülthoff, \& Noppeney, 2008). Response priming (for a review see, Schmidt, Haberkamp, \& Schmidt, 2011) investigates the effects of preactivation of motor responses from a prime event (i.e., a first stimulus) on the processing of a target event (i.e., a second stimulus that has to be categorized). Thus, response priming is a suitable tool to investigate the link between perception and action. Response priming has been investigated mainly using shape and color stimuli (Eimer \& Schlaghecken, 2002). Reaction times to the target often are reduced when the preceding prime stimulus and the target are associated with the same response (i.e., primes and targets are congruent, consistent, or compatible) compared with targets that are associated with another response (i.e., primes and targets are incongruent, inconsistent, or incompatible).

Bermeitinger (2013) found compatibility effects with moving row-of-dots prime stimuli on static arrow targets. The sign of the compatibility effect depended on the stimulus onset asynchrony (SOA) between prime and target. Essentially, with an SOA of $50 \mathrm{~ms}$, no priming was observed. With SOAs of 100 and $150 \mathrm{~ms}$, positive compatibility effects emerged. With SOAs between 250 and $500 \mathrm{~ms}$, negative compatibility effects emerged. This pattern appeared whether the SOA was varied between participants or within participants, and independent of prime duration. The reliable negative compatibility effect using moving primes is especially noteworthy, because clearly visible primes (motion stimuli) were used without any further constraints. In response priming variants using static primes, negative compatibility effects have frequently been found only when primes were masked (Eimer \& Schlaghecken, 2002). There is continuing debate about whether this pattern of effects is a result of motor or perceptual mechanisms and how many single processes (e.g., self-inhibition, mask-triggered inhibition, object updating, counting processes within different "evaluation windows" while accumulating evidence for one stimulus/category/response; attentional processes) contribute to this effect. Thus, it is especially interesting to investigate further the robust pattern found with moving prime stimuli.

However, until now only very specific motion types have been used for response priming with moving primes (Bermeitinger, 2013). The row-of-dots primes consisted of a row of 11 dots, which were horizontally aligned. These dots were "moved" toward the right, left, center, or toward the borders of the screen by shifting each dot some pixels to the right, left, center, or toward the border, respectively, after each refresh cycle. The shifting of the dots led to the impression that the dots themselves were moving. After every six refresh cycles (i.e., every $80 \mathrm{~ms}$ ), the dots returned to their original position and the movement started anew. This motion, using a moving row of dots that moved repeatedly along the same trajectory, was rather distinctive, and the question arises whether the results generalize to other motions or motion in general. Thus, the specific question is whether the results hinge on the fact (1) that a row of dots was used and (2) that this row's movement was repetitive, starting again from the original position every $80 \mathrm{~ms}$.

This last point in particular could be responsible for negative compatibility effects (see Stürmer, Aschersleben \& Prinz, 2000, who found negative correspondence effects in a Simon task with hand gestures as stimuli and responses when the go signals appeared after the turning point, i.e., the meaning [e.g., open/close] of the presented gesture). For example, it could be that due to the special properties of the stimulus presentation, namely the fact that the motion started again from the original position every $80 \mathrm{~ms}$, attention shifts after a certain period of time to the direction opposite that of the motion. That is, in the original experiments, there was motion in the opposite direction (after every $80 \mathrm{~ms}$ ), which could have been an external trigger to shift attention toward the incompatible direction, thus resulting in negative compatibility effects. Additionally, the use of a row of dots by itself can be questioned, because there is no precedent for using this type of presentation. To reiterate, the question arises as to whether the reversal from positive to negative compatibility effects with SOA generalizes to another kind of motion or is specific to the type of motion used in Bermeitinger (2013).

Thus, in the present studies we adapted the original experiments (Bermeitinger, 2013) to other motions that could be performed by other dot arrangements. This allowed us to investigate the constraints and mechanisms underlying the basic finding of a positive-followed-by-negative-compatibility effect pattern originally found with moving row-of-dots (Bermeitinger, 2013) and to study motions as priming events in response priming in general. Additionally, motions consisting of dots are frequently used stimulus objects when studying biological motion (Troje, 2013). In particular, pointlight stimuli often are used as visual experimental stimuli for biological motion perception studies (for review, Blake \& Shiffrar, 2007). 


\section{Point-Light Displays and other Biological Dot Stimuli}

Point-like displays consist of 10-15 light dots attached at relevant parts of a (human) body (i.e., joints, etc.). Typically, the body walks and the observer receives the impression of a walking human being solely by seeing the moving lights (Johansson, 1973). One can identify a point-light display as a human being very quickly (Johansson, 1976), and one is able to extract information on various characteristics from point-light walkers (e.g., sex) (Kozlowski \& Cutting, 1977; body size, Jokisch \& Troje, 2003; emotions, Dittrich, Troscianko, Lea, \& Morgan, 1996).

Besides these features, the walking direction of the living being perceived is important, because it allows the observer to assess crucial characteristics, such as constitution or intention. Walking direction can be detected quickly from seeing biological movements (Bertenthal \& Pinto, 1994; Chang \& Troje, 2008; 2009a; 2009b; Kuhlmeier, Troje \& Lee, 2010; Neri, Morrone \& Burr, 1998; see also Wang, Yang, Shi \& Jiang, 2014), it can trigger attention (Shi, Weng, He \& Jiang, 2010), and influence responses, even when it is task-irrelevant (Bosbach et al., 2004, 2005; Kourtzi \& Shiffrar, 1999; Thornton \& Vuong, 2004; Verfaillie, 2000).

There is an ongoing debate about how global and local motion elements contribute to the ability to perceive biological motion, its direction, and other relevant features (Beintema \& Lappe, 2002; Chang \& Troje, 2008; 2009a; Mather, Radford \& West, 1992; Troje, 2008; Thurman \& Grossman, 2008; Thurman \& Lu, 2013; Troje \& Aust, 2013; Troje \& Westhoff, 2006; Wang et al., 2014). For example, Beintema and Lappe (2002) tested biological motion perception with and without image motion signals and found above-chance recognition for both motion types. The authors concluded that performance does not improve with an increase of image motion signal. Furthermore. direction classification is above chance by only presenting paired fragments of moving feet of the point-light walker (Chang \& Troje, 2009a). Also, Wang and colleagues (2014) found a cuing effect of walking direction using only feet movements of point-light walkers. In summary, there is evidence for both global and local features of motion in point-light displays contributing to biological motion perception. Eventually, Chang and Troje (2009a; also Troje \& Westhoff, 2006) introduced the idea of two distinct mechanisms of biological motion perception: one innate, "life-detection" system, sensitive to local movements and focusing on individual dots, and one acquired system, sensitive to global shape and offering a more profound identification of specific characteristics of the living being.

Eye gaze is another frequently studied biological signal, especially for its impact on attentional shifts of the observer. Overall, perception of another person's gaze is a highly significant cue to shift one's attention. Eye gaze reveals a significant amount of information about the person who made the eye movements, for example, his direction of attention, or his emotional and mental state (Frischen, Bayliss, \& Tipper, 2007). In this line of research, gaze also is implemented by use of simple dots representing pupils or irises (Friesen \& Kingstone, 1998).

In general, the distinction between biological and nonbiological motions seems blurry. Many studies have used stimuli that vary on a continuum from less to more biological, rather than using stimuli that could be clearly defined as distinctively biological versus nonbiological. The present study follows in this mode as, for example, some of the trajectories of the point light displays in the control conditions are biological due to the fact that the control stimuli are reassembled from the pointlight walkers (Experiment 1-4). Thus, at a local level, there is still some "biological-ness," but at the global level (whole form), the control stimuli are no longer biological. One could refer to this difference as the "biological salience."

For the less biological point-light stimuli, we disrupted the global shape of the biological motion, but not completely, because both the upper and the lower part of the body were almost intact (Fig. 1d); that is, direction could still be retrieved from motion but no longer from shape. However, due to findings reporting that very few dots can carry directional information in this case (Chang \& Troje, 2009a; Troje \& Westhoff, 2006; Wang et al., 2014), the motion is biological to some degree and direction information might be mainly conserved. For the sake of brevity, we henceforth use the term "biological" when we speak of the condition or stimuli with a higher level of biological salience/biologicalness and the term "less biological" when referring to stimuli with a lower level of biological salience/biologicalness.

In summary, biological motion perception fulfills a special role in human information processing; that is, the ability to perceive biological movements is an important skill that allows us to extract crucial information about the moving creature (Dittrich et al., 1996; Jokisch \& Troje, 2003; Kozlowski \& Cutting, 1977), which helps us to develop expectations of its behavior and prepare appropriate responses. Biological signals, especially motions, are highly relevant social signals and can be used for coordinating actions interpersonally. When using biological signals, it seems especially interesting to vary timing parameters, because there are findings that own actions are adapted to the timing of perceived motion (Watanabe, 2008). There are local and global mechanisms that both distinctly contribute to biological motion perception and that can be separately investigated by modifying key aspects of the point-light displays, namely (among others) spatial configuration, acceleration, speed, use of masking dots, and orientation.

\section{Biological Motion in Congruency/Compatibility Tasks}

The findings of multiple studies investigating biologically moving stimuli, which utilized a variety of cognitive 
Fig. 1 Examples of one slide of the directional point-light motion stimuli used in Experiments 1 to 4. (a) Biological directional stimuli (i.e., normal walker); (b) less biological directional stimuli (i.e., split walker); (c) neutral point-light display; (d) construction of the split walker based on the normal walker. Three dots (marked in grey with white edgings) of the normal walker were not part of the split walker

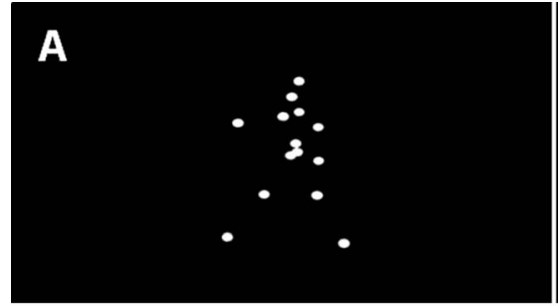

B

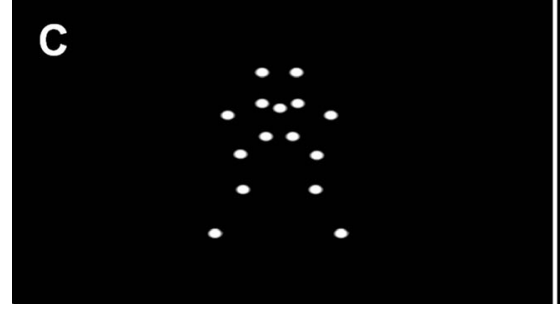

paradigms, can be compared with the response priming paradigm, in as much as they have investigated the influence of some kind of congruency or compatibility between a first and second stimulus on responses. Thornton and Vuong (2004) used point-light walkers in a flanker paradigm. Participants were asked to judge the direction of a central target (pointlight walker) that was flanked by a number of additional walkers, walking in the same (congruent trials) or different (incongruent trials) direction. All in all, responses in incongruent trials were found to be slower than in congruent trials. Interestingly, with scrambled points used as flanker figures, congruency did not influence response speed. Thus, the effect of biological motion in the flanker task might be due to global rather than local processing of motion. Shi and colleagues (2010) used dynamic and static point-light displays in a central cuing experiment and found positive effects of attentional orienting toward the point-light motion displays but not toward inverted motion, static, or nonbiological object motion displays. Furthermore, they varied the SOA: positive effects of orienting were found with SOAs of $300 \mathrm{~ms}$ and $600 \mathrm{~ms}$, but not $1100 \mathrm{~ms}$. Wang and colleagues (2014) reported comparable findings with local biological moving stimuli: When a fragment of a biological point-light display (feet) walking to the left or to the right was shown before a cue on either the left or the right side of fixation, responses were faster when walking direction and target position were corresponding. The effect was found even without explicit recognition of the movements as "biological." Bosbach et al. (2004, Exp. 4; see also Bosbach et al., 2005) conducted an experiment on the Simon effect using point-light walkers that turned red or blue after a short time. The colors that participants had to judge were mapped onto left and right response keys. A positive effect in terms of shorter RTs in trials with walking direction corresponding to response key was shown using upright walkers but was absent using inverted or static walkers. In contrast to Thornton and Vuong (2004), (dynamic) scrambled points also influenced response latencies in this way (Bosbach et al.,
2004, Exp. 5). A comparable experiment was conducted by Hirai, Saunders, and Troje (2011). Participants saw a pointlight walker and a dot at each side of the walker. As in Bosbach et al. (2004), the point-light walker took on a color, which now served as a signal for participants to move their eyes to the left or to the right dot. Eye movements were recorded. In compatible trials (point-light walker direction corresponding to eye movement direction), response latencies were shorter than in incompatible trials for the point-light walker but not for scrambled points. However, scrambling all points except those representing the feet produced similar effects as the (coherent) point-light walker.

Taken together, biologically moving stimuli have been used in cognitive paradigms on spatial orientation, attention, or processing of distracting stimuli. In all cases, they have been shown to influence task performance significantly, even when they were not recognized as biological (Wang et al., 2014) or when they were task-irrelevant (Bosbach et al., 2004; Hirai et al., 2011; Thornton \& Vuong, 2004). However, there are inconsistent findings - in what way scrambled points affect RTs in a particular task and to what extent global and local mechanisms contribute to response effects.

In summary, there is evidence of congruency effects using motion stimuli. The first goal of the present experiments was to use other dot stimuli than already used in Bermeitinger (2013) to further investigate the positive-followed-by-negativecompatibility effects pattern found therein. In Bermeitinger (2013), completely nonbiological and abstract motions were used. By use of less biological motions, we used other (overall) abstract motions. We expected positive compatibility effects with shorter SOAs and negative compatibility effects with longer primes, if the pattern of results found by Bermeitinger (2013) is generally observable with any motion. The second goal of our experiments was to test whether response priming in the narrow sense as described above (prime and target match or do not match regarding the response they evoke) could be a useful tool to study the processing of visually perceived biological motion and one 
aspect of the links between perception and action. In the tradition of early experiments on motion perception and to remain similar to the stimuli used in the original experiment (Bermeitinger, 2013: which used stimuli consisting of dots), we used pointlight walkers as primes in Experiments 1 to 4. In Experiments 5 and 6, we broadened the focus and used another biological motion (i.e., gaze), also realized by moving dots (representing irises and pupils). We were able to compare the same dot motion with or without biological information.

\section{Experiment 1}

In Experiment 1, we used shortly presented point light displays as primes in a response priming experiment. First, there were normal upright point-light walkers (henceforth "normal walker") walking toward the right or left as biological primes. Second, there were walkers adapted from the normal walker, by horizontally cutting it in half, and putting the two parts back together, moving the bottom half to the top and vice versa (henceforth "split walkers") as less biological primes. The split walkers were less biological due to two aspects: (1) the global biological form was destroyed, and (2) local motions (e.g., from the feet) were at different-and unexpected-places compared with the normal walker (Hirai et al., 2011). Additionally, we used neutral baseline conditions with nondirectional point-light displays. Left- and right-pointing static arrows were used as targets, following Bermeitinger (2013) who showed compatibility effects with simple nonbiological motion primes and static arrows as targets. The participants' task was to classify the arrow's direction by pressing the left/right key with their left/right index finger. Thus, we are able to analyze the influence of response preactivations caused by directional movements on the execution of left and right responses. SOA was varied in three steps: 147,360 , and $800 \mathrm{~ms}$. Given the results of Bermeitinger (2013) with simple moving dot stimuli, large compatibility effects were expected. In the SOA condition with $150 \mathrm{~ms}$, she reported a positive compatibility effect with an effect size of $d=0.84$. It can be stated that the compatibility effect in our $147 \mathrm{~ms}$ SOA condition-if we concede its existence - can be detected with probability 1- $\beta=0.95$ $(\alpha=0.05)$ if one uses a sample size of at least $N=17$ (Erdfelder, Faul, \& Buchner, 1996). The corresponding effect in the $360 \mathrm{~ms}$ SOA condition of $d=1.05$ and the effect in the longest SOA condition of $d=1.03$ (500 ms in Bermeitinger, 2013) can be detected with $1-\beta=0.95(\alpha=0.05)$ if one uses a sample of at least $N=12$, respectively.

\section{Method}

Participants Seventy-nine students from the University of Hildesheim (71 women and 8 men), ranging in age from 18 to 38 years ( $M d=22$ years) participated in the present experiment. They were either paid or obtained partial course credit for their participation. All participants had normal or corrected-to-normal vision. The experiment was conducted at two separate periods of time: in the first period, the $147 \mathrm{~ms}(n=33)$ and $360 \mathrm{~ms}(n=30)$ SOA conditions were conducted (participants were assigned to one of the two SOA conditions), and in the second period, the $800 \mathrm{~ms}(n=16)$ SOA condition was conducted.

Design The experiment used a $3($ SOA: $147,360,800 \mathrm{~ms}) \times 2$ (biologicalness: biological, less biological movement) $\times 3$ (compatibility: compatible, incompatible, neutral) design. The first factor (SOA) was varied between participants. The other factors (compatibility and biologicalness) were varied trial-by-trial within participants. The prime stimulus in each trial was either an upright point-light walker (immediate impression of biological motion) or a split point-light walker (weaker to no impression of biological motion). Besides that, in each trial, the prime and target stimuli either indicated the same direction (compatible) or different directions (incompatible). In one third of all trials, the prime stimulus did not indicate any direction (neutral).

Stimuli Three different types of prime stimuli were used: normal (upright) point-light walkers, split point-light walkers (Fig. 1), and neutral point-light motions. The entire movement sequence of the point patterns in both biologicalness conditions (biological, less biological movement) was presented stationary (as if on a treadmill; i.e., the light dots on average did not actually move closer to the side of the screen). For normal and split walkers, primes were created in which the walking direction was toward the left or right boarder of the screen. The left motion primes were simply created by vertically mirroring each slide of the right motion primes.

Normal walkers consisted of 14 light dots, arranged as a human being. They were similar to the walkers presented by the Biomotionlab (http://www.biomotionlab.ca) as well as to the walker from the action database of point-light animations by Vanrie and Verfaillie (2004) with slight modifications. First, in the present experiment, PLW's dots should have a more similar size to the dots of the row-of-dots primes used before (Bermeitinger, 2013). Besides, in our experiments, participants viewed the PLWs for a very short amount of time, but the impression of the walkers themselves and also their motion direction should be highly recognizable and salient. To live up to these demands, we used slightly modified pointlight walkers. Compared with the animations by Vanrie and Verfaillie, they had (1) larger individual dots (in relation to the body size), (2) one additional dot approximately in the center of the body, and (3) a higher relation of width (i.e., horizontal distance between the rightmost and leftmost dots) and body height as to arm width (width : height $0.5: 1)$, leg width (0.34: $1)$, and foot width $(0.8: 1)$. Through these changes, the dynamic distance of extremity movements increased to make the 
movement more salient. (The 2-D coordinates of left and right walkers is in the Appendix).

The walkers were shown in sagittal view (i.e., facing toward the right or left). We created a single slide for each refresh cycle that the walker was presented. The height of the point-light walker was approximately $8 \mathrm{~cm}\left(7.64^{\circ}\right.$ visual angle) and the width between 4.5 and $6.5 \mathrm{~cm}\left(5.25^{\circ}\right.$ visual angle). Each prime was presented overall for $120 \mathrm{~ms}$, consisting of 9 succeeding slides (each for approximately 13 $\mathrm{ms}$; refresh rate was $75 \mathrm{~Hz}$ ). The whole gait cycle consisted of 32 slides. Only a gait fragment, $56.25 \%$ of a gait cycle (slides $1-9)$, was shown as primes. Note that the discrimination of the direction of a point-light walker is possible when observing very short point light displays and/or only fragments of a gait cycle (Chang \& Troje, 2008, 2009a, 2009b). However, sensitivity for biological motion and/or motion direction is not uniform across the gait cycles (Thurman \& Grossman, 2008). Due to this, first, the left and right walkers always started with the same slide, respectively, and always the same gait fragment was shown. Second, to make the biological and less biological conditions more comparable regarding the diagnosticity for direction, we chose a normal walker fragment that have been found to be only slightly diagnostic (Thurman \& Grossman, 2008). These were displays shortly before and after the most horizontal spread of the extremities.

For the less biological condition, split walkers were created. They contained a similar number of light dots (11). The dots were adapted from the normal walker, by horizontally cutting the point-light walkers of slides 7 to 15 in half, and putting the two parts back together, moving the bottom half to the top and vice versa (Fig. 1). The images for the split walkers had a similar height $\left(8.5 \mathrm{~cm} ; 8.11^{\circ}\right.$ visual angle $)$ and width $\left(2.0-5.0 \mathrm{~cm} ; 3.34^{\circ}\right.$ visual angle) as the point-light walkers.

For the neutral conditions, essentially, the normal pointlight walker were vertically divided into two parts, from which the front part was mirrored and put next to the original front part (discarding the rear part), resulting in a light dot combination with 15 dots that moved symmetrically to both sides. Neutral primes in the biological movement condition were the same as those in the less biological movement condition, but they were allocated a priori to one of the two conditions (biological, less biological).

The target stimuli were arrows, pointing either to the left or right. They were presented at the center of the screen. The arrows were approximately $4 \mathrm{~cm}$ in length and $1.6 \mathrm{~cm}$ in height $\left(3.82^{\circ}\right.$ visual angle). All stimuli and instructions were presented in white on a black background.

Procedure Participants were individually tested in small, soundattenuated chambers. A computer screen (17" CRT monitor, screen resolution $640 \times 480$ pixels) was placed approximately $60 \mathrm{~cm}$ in front of them. The experiment was run using E-Prime software (version 1.3) with standard PCs. Instructions were given on the screen. Participants were required to make responses with their left or right index finger, depending on the side the target arrows pointed to (response keys were the 1 and the 3 key on the numeric pad, which had arrow stickers pasted on them). Participants were instructed to respond as quickly and as accurately as possible. The experiment consisted of 4 blocks, each containing 72 trials. Half of the trials in each block used the normal walker and the split walker primes, respectively. Each half comprised one third compatible, incompatible, and neutral trials. Within each block, trials were chosen randomly by the computer. After each block, the participants were given the chance to have a short rest. Before the experimental blocks, participants worked through a practice block with 12 trials.

Each experimental trial started with a fixation cross (1000 $\mathrm{ms}$ ). After that, 9 displays of light dots were shown (primestimulus; $120 \mathrm{~ms}$ total duration) at the center of the screen. Subsequently, a blank display appeared for 27,240 , or $680 \mathrm{~ms}$ for the 147,360 , and $800 \mathrm{~ms}$ SOA condition, respectively. Then, the target-stimulus (arrow to the left or to the right) appeared at the center of the screen, until a classification response was given by the participant. The blank-screen intertrial interval lasted $400 \mathrm{~ms}$.

\section{Results}

For the analysis of reaction times, only correct responses were used (mean error rate was $2.1 \%$ of all trials; correlations showed that RTs and error rates went into the same direction or were not correlated). Outlying RTs that were 1.5 interquartile ranges above the third quartile with respect to the individual distribution (Tukey, 1977) were discarded, as well as RTs above 1,500 and below $200 \mathrm{~ms}$. These constituted $5.6 \%$ of all trials. Table 1 shows mean response times and errors in all conditions. A mixed analysis of variance (ANOVA) of the RTs was performed with the factors SOA (147, 360, $800 \mathrm{~ms})$, biologicalness (biological, less biological movement), and compatibility (compatible, incompatible, neutral). If necessary, the number of degrees of freedom, $p$ values and MSEs were corrected in all following ANOVAs according to the Greenhouse-Geisser method.

The main effect of SOA was not significant, $F<1$. The factor biologicalness showed a marginal effect, $F(1,76)=$ $3.38, M S E=52.08, p=0.07, \eta_{\mathrm{p}}{ }^{2}=0.04$, indicating a tendency for faster responses in trials with normal walker primes compared with split walker primes. Most importantly, prime-target compatibility had a significant influence on RTs, $F(1.27$, $96.28)=76.71, M S E=315.02, p \leq 0.001, \eta_{\mathrm{p}}{ }^{2}=0.50$. Repeated contrasts showed that correct responses were faster in compatible trials compared with neutral trials, $F(1,76)=$ $36.65, M S E=191.96, p \leq 0.001, \eta_{\mathrm{p}}{ }^{2}=0.33$, and faster in neutral trials compared with incompatible trials, $F(1,76)=$ 82.12, MSE $=310.44, p \leq 0.001, \eta_{\mathrm{p}}{ }^{2}=0.52$, indicating a general positive compatibility effect to which facilitation (faster reactions to compatible than neutral trials) as well as 
Table 1 Mean response times (in $\mathrm{ms}$; errors in $\%$ in parenthesis) as a function of prime-targetcompatibility, movement condition (biological vs. less biological), and SOA in Experiments 1, 3, 4, 5, and 6

\begin{tabular}{|c|c|c|c|c|c|c|}
\hline & \multicolumn{3}{|l|}{ Biological } & \multicolumn{3}{|c|}{ Less biological } \\
\hline & Compatible & Neutral & Incompatible & Compatible & Neutral & Incompatible \\
\hline \multicolumn{7}{|c|}{ Exp. 1 (normal walker vs. split walker) } \\
\hline SOA 147 & $325(0.8)$ & $343(1.8)$ & $372(7.6)$ & $344(1.8)$ & $345(1.8)$ & $349(1.8)$ \\
\hline SOA 360 & $333(1.4)$ & $350(0.9)$ & $370(4.6)$ & $351(0.9)$ & $349(1.3)$ & $364(2.0)$ \\
\hline SOA 800 & $336(1.0)$ & $342(0.9)$ & $348(2.6)$ & $340(1.0)$ & $341(2.1)$ & $347(2.7)$ \\
\hline \multicolumn{7}{|c|}{ Exp. 3 (normal walker vs. split walker; $L$ and $R$ as targets) } \\
\hline SOA 147 & $410(1.2)$ & $405(2.6)$ & $420(4.6)$ & $409(2.2)$ & 407 (1.9) & $416(1.9)$ \\
\hline SOA 350 & $390(1.3)$ & $395(1.9)$ & $408(4.7)$ & $405(1.0)$ & $398(1.2)$ & $410(1.6)$ \\
\hline SOA 800 & $379(1.3)$ & $389(2.0)$ & $398(3.6)$ & $389(1.7)$ & $388(1.6)$ & $392(3.3)$ \\
\hline \multicolumn{7}{|c|}{ Exp. 4 (normal walker vs. split walker) } \\
\hline SOA 920 & $339(0.8)$ & $341(1.0)$ & $344(1.6)$ & $340(0.4)$ & $340(1.2)$ & $344(1.0)$ \\
\hline SOA 1320 & $344(1.3)$ & $345(0.9)$ & $348(1.4)$ & $346(1.0)$ & $344(1.1)$ & $351(1.9)$ \\
\hline \multicolumn{7}{|c|}{ Exp. 5 (gaze in schematic face vs. dots) } \\
\hline SOA 307 & $346(0.6)$ & $379(0.8)$ & $393(4.9)$ & $351(0.7)$ & $368(1.1)$ & $385(2.9)$ \\
\hline SOA 600 & $345(1.6)$ & $350(2.1)$ & $356(2.5)$ & $346(2.0)$ & $348(1.5)$ & $349(2.8)$ \\
\hline \multicolumn{7}{|c|}{ Exp. 6 (gaze in schematic face vs. dots in geometrical line drawing) } \\
\hline SOA 307 & $343(0.9)$ & $385(1.7)$ & $403(12.3)$ & $347(1.1)$ & $377(1.6)$ & $388(5.8)$ \\
\hline SOA 600 & $336(4.4)$ & $336(2.2)$ & $337(3.5)$ & $337(3.8)$ & $335(1.9)$ & $332(2.6)$ \\
\hline
\end{tabular}

restriction (from incompatible primes, i.e., slower reactions to incompatible than neutral trials) contributed.

Besides the significant main effect of compatibility, all two-way and the three-way interactions were significant: biologicalness $\times$ SOA: $F(2,76)=3.67, M S E=52.08, p \leq$ $0.05, \eta_{\mathrm{p}}{ }^{2}=0.09$; compatibility $\times$ SOA: $F(2.53,96.28)=$ $4.57, M S E=315.02, p \leq 0.01, \eta_{\mathrm{p}}{ }^{2}=0.11$; biologicalness $\times$ compatibility: $F(1.50,114.33)=50.85, M S E=126.66, p \leq$ $0.001, \eta_{\mathrm{p}}{ }^{2}=0.40 ;$ SOA $\times$ biologicalness $\times$ compatibility: $F(3.01,114.33)=12.27, M S E=126.66, p \leq 0.001, \eta_{\mathrm{p}}{ }^{2}=0.24$.

To further clarify these interactions, we subsequently conducted ANOVAs separately for the biological and less biological movement condition.

Biological movement condition The 3 (SOA) x 3 (primetarget compatibility) ANOVA in the biological movement condition revealed no significant main effect of SOA, $F<1$. A significant main effect of compatibility was found, $F(1.32$, $100.10)=100.59, M S E=277.07, p \leq 0.001, \eta_{\mathrm{p}}{ }^{2}=0.57$, as well as a significant interaction of both factors, $F(2.63$, $100.10)=9.70, M S E=277.07, p \leq 0.001, \eta_{\mathrm{p}}{ }^{2}=0.20$.

We conducted one-sample $t$ tests (comparing to zero) for each SOA condition. The results showed that compatibility effects of each SOA condition were significantly above zero, SOA 147: $M=47 \mathrm{~ms}, S D=25.97, t(32)=10.49, p \leq 0.001$; SOA 360: $M=37 \mathrm{~ms}, S D=28.00, t(29)=7.15, p \leq 0.001$; SOA 800: $M=12 \mathrm{~ms}, S D=14.11, t(15)=3.38, p \leq 0.01$ (Fig. 2). As revealed by Scheffé tests, differences were found between the compatibility effects in the 147 and $800 \mathrm{~ms}$ SOA conditions, $S E=7.60, p \leq 0.001$, as well as between the compatibility effects in the 360 and $800 \mathrm{~ms}$ SOA conditions, $S E=7.72, p \leq 0.01$. There was no significant difference between the compatibility effects in the 147 and $360 \mathrm{~ms}$ SOA conditions, $S E=6.29, p=0.23$. These results suggest that the shorter SOAs (147 and $360 \mathrm{~ms}$ ) are associated with very strong positive compatibility effects and that the longer SOA ( $800 \mathrm{~ms})$ is associated with a weaker, but still positive, effect.

Less biological movement condition The same analysis for the less biological condition was conducted. There was no significant main effect of SOA, $F=1.13, p=0.33$. Comparable with results in the biological condition, both a significant main effect of compatibility was found, $F(1.38$, $105.21)=15.99, M S E=162.31, p \leq 0.001, \eta_{\mathrm{p}}{ }^{2}=0.17$, as well as a significant interaction of both factors, $F(2.77,105.21)=$ 2.77, $M S E=162.31, p \leq 0.05, \eta_{\mathrm{p}}{ }^{2}=0.07$.

In contrast to the biological condition, one-sample $t$ tests in the less biological condition showed significant compatibility effects only in the 360- and 800-ms SOA conditions (SOA 360: $M=14$ $\mathrm{ms}, S D=20.12, t(29)=3.75, p \leq 0.001$; SOA $800: M=7 \mathrm{~ms}, S D$ $=10.00, t(15)=2.88, p \leq 0.01)$ but not in the $147 \mathrm{~ms}$ SOA condition (SOA 147: $M=5 \mathrm{~ms}, S D=21.63, t(32)=1.44, p=$ 0.16 ) (Fig. 2). Scheffé comparisons did not reveal any differences between compatibility effects of different SOA conditions in the less biological condition (all $p \mathrm{~s}>0.23$ ).

\section{Discussion}

Experiment 1 was conducted to investigate other directional motion stimuli as primes than used in Bermeitinger (2013) 


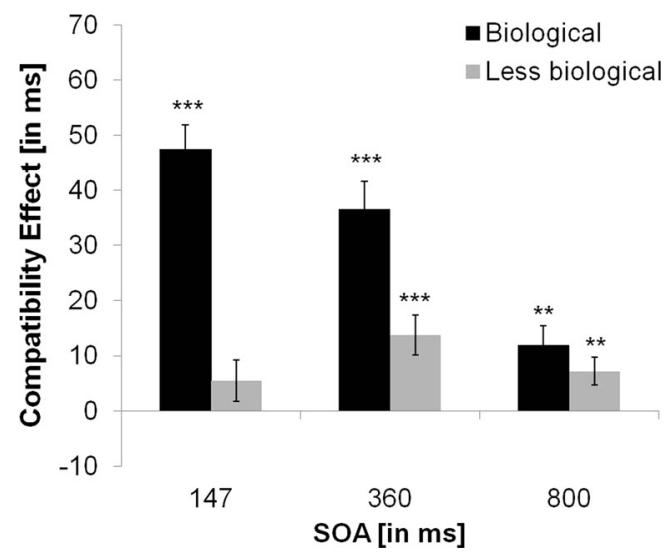

Fig. 2 Compatibility effects (in ms). Differences in RTs between compatible and incompatible trials for trials using the normal walker (i.e., biological condition) and the split walker (i.e., less biological condition) as primes, separately depicted for the three different SOA conditions in Experiment 1. Error bars represent the standard error of the mean. ${ }^{* * *} p \leq 0.001,{ }^{* *} p \leq 0.01$

where a positive-followed-by-negative-compatibility effect pattern depending on SOA was found with moving row-ofdots primes. In Experiment 1, we used other motion stimuli that were realized by arrangements of dots, i.e., point-light normal walkers (biological) versus split walkers (less biological). Results of Experiment 1 showed no evidence for negative compatibility effects associated with longer SOAs. However, there were large compatibility effects with biological primes, but smaller effects with less biological primes. Before interpreting the results in relation to the findings of previous experiments and/or as evidence that the degree of biological salience may cause this difference, we wanted to test (1) whether biological and less biological stimuli also differ regarding the extent of directionality (Experiment 2) and (2) whether attentional orienting might play a role when directional targets had to be discriminated (Experiment 3).

\section{Experiment 2}

In Experiment 1, we found clear evidence for differences between biological and less biological motion in a response priming study. One interpretation of larger compatibility effects with biological motions might be that biological motions are more able to trigger associated own motor responses. However, there are some alternative explanations that we wanted to test in the following experiments. The first alternative explanation could be that biological and less biological motion, as used in Experiment 1, differ in the extent to which information on directionality is available. For example, Chang and Troje (2009b) found differences between coherent and scrambled walkers in a direction discrimination task: walking direction was better detected when coherent walkers were presented (error rate across all blocks and mask density levels: $12 \%$ ) than when scrambled stimuli were presented (error rate across all blocks and mask density levels: $32 \%$ ). Thus, in Experiment 2, we tested direction discrimination of the biological, less biological, and neutral stimuli used in Experiment 1 by asking participants directly to respond to the direction of the point-light displays.

\section{Method}

Participants Thirty-three students from the University of Hildesheim (28 women and 5 men), ranging in age from 19 to 36 years ( $M d=22$ years), were analyzed for the present experiment. Three further participants had to be excluded from analysis due to technical reasons during data acquisition. Participants were either paid or obtained partial course credit for their participation. All participants had normal or corrected-to-normal vision.

Design In the experiment, one crucial factor (biologicalness: biological, less biological, neutral movement) was varied within participants. Additionally, the biological and less biological walker could walk toward the right or left.

Stimuli and Procedure Stimuli were the prime stimuli as used in Experiment 1. The procedure of the experiments was similar to those in Experiment 1 with the two exceptions. The first exception was that participants had to respond directly to the walking stimuli by classifying their motion direction as either left (by pressing number 1 on the number pad, which had an " $L$ " label pasted on it, with the left index finger), right (by pressing number 3 on the number pad, which had an " $R$ " label pasted on it, with the right index finger), or neither/nor (by pressing "Enter" on the number pad, which had a "W/N" label for weder/noch (neither/nor) pasted on it, with the right middle finger). Again, participants were instructed to respond as quickly and accurately as possible. As before, the experiment consisted of 4 blocks, each containing 72 trials. Onesixth of the trials in each block used the normal walker left, the normal walker right, the split walker left, and the split walker right. The neutral motion was used in one-third of all trials. Within each block, trials were chosen randomly by the computer. After each block, the participants were given the chance to have a short rest. Before the experimental blocks, participants worked through a practice block with 12 trials.

The second exception was that the trial procedure was slightly different to Experiment 1 . The most important difference was that there was no target stimulus. Each experimental trial started with a fixation cross $(1000 \mathrm{~ms})$. After that, nine displays of light dots were shown (120 ms total duration) at the center of the screen. Subsequently, a blank display appeared for $27 \mathrm{~ms}$. Then, the (blank) response display appeared until a classification response was given by the participant (thus, the SOA between prime onset and possibility to 
respond was the same as in Experiment 1 for the short SOA). To indicate that the response was given, the screen changed into grey for $400 \mathrm{~ms}$. The black blank-screen intertrial interval lasted $200 \mathrm{~ms}$.

\section{Results}

We measured the error rates in each biologicalness condition $\left(M_{\text {biological }}=22.57 \%, S D=34.85 ; M_{\text {less biological }}=9.28 \%, S D\right.$ $\left.=15.87, M_{\text {neutral }}=17.14 \%, S D=26.47\right)$ as an index for direction discrimination performance (Chang \& Troje, 2009b) and performed a repeated measures ANOVA. The GreenhouseGeisser correction was applied. The main effect of biologicalness was not significant, $F(1.38,44.19)=2.47$, $M S E=865.84, p=0.11, \eta_{\mathrm{p}}{ }^{2}=0.07$. Contrasts showed that more errors were made in the biological than the less biological condition, $F(1,32)=4.72, M S E=1234.20, p \leq 0.05, \eta_{\mathrm{p}}{ }^{2}=$ 0.13 , and more errors in the neutral than the less biological condition, $F(1,32)=4.22, M S E=483.68, p \leq 0.05, \eta_{\mathrm{p}}{ }^{2}=$ 0.12 , but there was no difference in error rates between the biological and neutral conditions, $F<1, p>0.52$.

\section{Discussion}

The results of Experiment 2 showed clearly that directionality can be extracted from our less biological stimuli at least as well as from our biological stimuli. This seems to stand slightly at odds with the results by Chang and Troje (2009b). However, first, we used even shorter motion stimuli than their shortest stimulus durations were. Second, they also used masks to reduce the visibility of their stimuli. Third, we explicitly chose fragments of the gait cycles of the biological motions that have been found to be slightly diagnostic (see above). In summary, Experiment 2 can be seen as evidence that the larger compatibility effects with biological motion primes in Experiment 1 are not caused by a greater ability to determine directionality of biological motion displays. One might further assume that subjects extract the directional information from different aspects of the biological versus less biological walker (e.g., coherent structure vs. local motion, respectively). However, this could explain the differences in priming effects in Experiment 1 only if one additionally assumes that the subjects pay attention to different aspects of the walker in dependency of the task that they have or that one aspect of the walker triggers their responses differently (in dependency of the task).

With the large compatibility effects found in Experiment 1, it is surely implausible to argue that directional information cannot be extracted from the prime stimuli, whether they are biological or less biological. We interpret the results of Experiment 2 as clear evidence that the smaller priming effects with less biological material (Experiment 1) cannot be attributed to the fact that the less biological material contains less directional information.

\section{Experiment 3}

Another alternative explanation for the results of Experiment 1 depends on attentional effects, because it could be that biological movements have a greater capacity to trigger attentional shifting than less biological movements. Specifically, an attentional shift toward the direction of the motion would lead to benefits in perceiving and discriminating, and in consequence responding to, compatible targets, which are defined as targets where the tip of the arrow is in the same location as that where attention was shifted by the preceding prime (in compatible trials). Two things should be noted. First, such explanations also hold true for response priming with static stimuli; that is, explanations in terms of attentional shifting with better discrimination of arrow targets in compatible cases as the tip of the arrow than is in the focus of attention - are not specific to experiments with moving stimuli. Second, Bermeitinger (2013) previously indicated that attentional processes may partially explain the results of her response priming experiments with row-of-dots primes. Nevertheless, in Experiment 3 we used a new set of two stimuli as targets; that is, we used the letters L (requiring a left finger's response) and $\mathrm{R}$ (requiring a right finger's response). Now, the targets contained the discriminative features in compatible trials, while remaining spatially neutral in relation to where attention may have been shifted in response to the primes. Thus, the relationship between primes and targets is solely based on the response triggered or required by them. When attention is shifted toward the prime's direction, this would be no more benefit in discriminating the targets in compatible cases. However, the use of the letters $\mathrm{L}$ and $\mathrm{R}$ reflect some kind of compromise: the assignment to left and right finger responses is not as pronounced to the same extent as the assignment of left and right arrows to left and right responses. In turn, encoding, assignment, and responding to the new targets are probably somewhat different to that of arrow targets.

\section{Method}

Participants In Experiment 3, 53 students from the University of Hildesheim (44 women and 9 men) were analyzed. They participated in exchange for money or course credit (age ranging from 17 to $40, M d=22$ years). They were randomly assigned to one of the three SOA conditions. In the 147-ms SOA condition, 19 persons were tested. In the $360-\mathrm{ms}$ SOA condition, 18 persons were tested. In the $800-\mathrm{ms}$ SOA condition, 16 persons were tested. Two further participants were tested, but they were excluded from further analysis due to technical problems during data acquisition.

Design, Stimuli, Procedure We used the same design, stimuli, and procedure as in Experiment 1 with the exception that the targets were now the letters $\mathrm{L}$ and $\mathrm{R}$ to which participants had 
to respond with a left and right key press ( $\mathrm{L}$ and $\mathrm{R}$ were pasted on the keys) with their left and right index fingers, respectively.

\section{Results}

Mean error rate was $2.2 \%$ of all trials (correlations showed that RT and error rate effects went into the same direction or were not correlated). Reaction times were treated as in Experiment 1, resulting in $5.5 \%$ of all trials being discarded. Mean response times and errors are shown in Table 1.

A 3 (SOA: 147, 360, $800 \mathrm{~ms}$ ) $\times 2$ (biologicalness: biological, less biological) $\times 3$ (compatibility: compatible, incompatible, neutral) mixed ANOVA yielded no main effect of SOA, $F(2$, $50)=1.72, p=0.18$, but a significant main effect of the factor biologicalness, $F(1,50)=4.53, M S E=94.38, p<0.05, \eta_{\mathrm{p}}{ }^{2}=$ 0.08 , indicating slightly faster responses in trials with normal walker primes compared to split walker primes. Importantly, there was a significant main effect of prime-target compatibility, $F(1.65,82.66)=38.37, M S E=121.52, p \leq 0.001, \eta_{\mathrm{p}}{ }^{2}=0.43$. Repeated contrasts showed that responses were faster in neutral trials compared to incompatible trials, $F(1,50)=75.25, M S E=$ 154.27, $p \leq 0.001, \eta_{\mathrm{p}}{ }^{2}=0.60$, whereas response time in compatible and neutral trials did not differ, $F<1$, indicating a general positive compatibility effect to which overall solely restriction (from incompatible primes, i.e., slower reactions to incompatible than neutral trials) contributed.

Furthermore, the following interactions were significant: biologicalness $\times$ SOA: $F(2,50)=4.56, M S E=94.29, p \leq$ $0.05, \eta_{\mathrm{p}}{ }^{2}=0.15$; biologicalness $\times$ compatibility: $F(2,100)=$ 9.12, MSE $=223.55, p \leq 0.001, \eta_{\mathrm{p}}{ }^{2}=0.15$; SOA $\times$ biologicalness $\times$ compatibility: $F(4,100)=2.44, M S E=$ $291.70, p \leq 0.05, \eta_{\mathrm{p}}{ }^{2}=0.09$. To further clarify these interactions, we subsequently conducted ANOVAs separately for the biological and less biological movement condition.

Biological movement condition The 3 (SOA) x 3 (primetarget compatibility) ANOVA in the biological movement condition revealed no significant main effect of SOA, $F(1$, $50)=1.90, p=0.16$. A significant main effect of compatibility was found, $F(2,100)=39.01, M S E=95.40, p \leq 0.001, \eta_{\mathrm{p}}{ }^{2}=$ 0.44 , as well as a significant interaction of both factors, $F(4$, $100)=2.96, M S E=95.40, p \leq 0.05, \eta_{\mathrm{p}}{ }^{2}=0.11$.

We conducted one-sample $t$ tests (comparing to zero) for each SOA condition. The results showed that compatibility effects of each SOA condition were significantly above zero, SOA 147: $M$ $=10 \mathrm{~ms}, S D=17.48, t(18)=2.51, p \leq 0.05$; SOA 360: $M=18$ $\mathrm{ms}, S D=14.82, t(17)=5.26, p \leq 0.001$; SOA $800: M=20 \mathrm{~ms}$, $S D=14.06, t(15)=5.56, p \leq 0.001$ (Fig. 3). As revealed by Scheffe tests, the priming effects in the three SOA conditions were equally large (all $p \mathrm{~s}>0.74$ ).

Less biological movement condition The same analysis for the less biological condition was conducted. There was no significant main effect of SOA, $F=1.62, p=0.21$. Importantly, there was a significant main effect of compatibility, $F(2,100)=10.02, M S E=96.75, p \leq 0.001, \eta_{\mathrm{p}}{ }^{2}=0.17$, but no interaction of the factors, $F<1$.

In contrast to the biological condition, one-sample $t$ tests in the less biological condition showed only a significant compatibility effect in the $147 \mathrm{~ms}$ SOA condition, $M=7 \mathrm{~ms}, S D=$ $12.12, t(18)=2.65, p \leq 0.05$, but no significant compatibility effects in the 360 and $800 \mathrm{~ms}$ SOA condition (SOA 360: $M=$ $5 \mathrm{~ms}, S D=17.82, t(17)=1.10, p=0.28$; SOA $800: M=3 \mathrm{~ms}$, $S D=15.67, t<1$ ) (Fig. 3). Comparable to the biological condition as well as to the less biological condition in Experiment 1, Scheffé comparisons did not reveal any differences between compatibility effects of different SOA conditions in the less biological condition (all $p \mathrm{~s}>0.21$ ).

\section{Discussion}

In Experiment 3, we used exactly the same procedure as in Experiment 1 with the only exception being the form of the targets. Instead of using left and right pointing arrows, we now used the letters $\mathrm{L}$ and $\mathrm{R}$, thus eliminating the possibility that the targets can be better discriminated based on the shifting of attention to a particular location following the primes, as may be argued for arrow targets. Nevertheless, the overall finding of larger compatibility effects with biological than less biological motion primes was replicated. In contrast to Experiment 1 , the compatibility effects with biological motion primes did not differ between SOAs; that is, they were of comparable height irrespective of timing parameters. The same holds true for less biological motion conditions: compatibility effects did not differ between SOA conditions. However, the only significant single effect with less biological motion primes was found with the shortest SOA. Additionally, in this condition, we did not find a difference for compatibility effects between biological and less biological motion primes and the compatibility effects in this condition were-compared with Experiment 1 -relatively small. As mentioned, the assignment of letter targets to responses is not as automatic as that of arrow targets (Eimer \& Schlaghecken, 1998, actually found no evidence for compatibility effects of [masked] arrow primes on target letters). This also is shown in response times, which were clearly slower in Experiment 3 than in Experiment 1. One might argue that the benefits of automatic and large response preactivations in compatible trials due to the primes are already vanished when responses eventually can be executed. Nevertheless, we found clear positive compatibility effects. Additionally, we found no evidence for negative compatibility effects with the SOAs used in Experiment 1 and 3, and we found larger compatibility effects with biological than less biological motion primes. Overall, the results might be interpreted as evidence that motion primes, especially biological motion primes, are rather strong cues to trigger actions. 


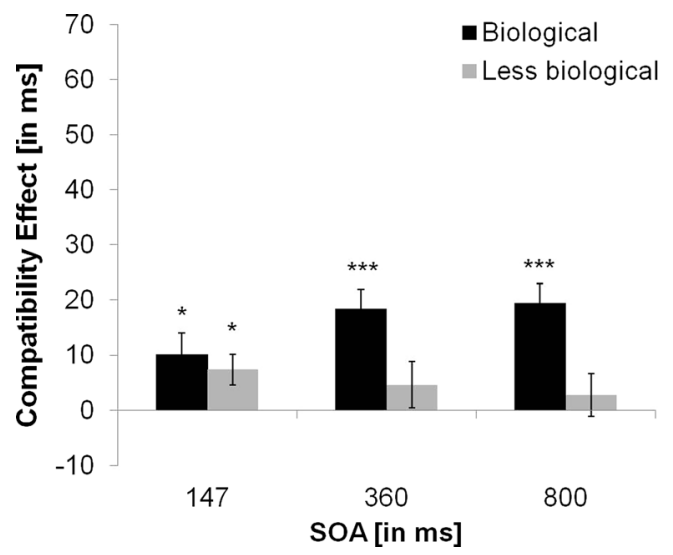

Fig. 3 Compatibility effects (in $\mathrm{ms}$ ). Differences in RTs between compatible and incompatible trials for trials using the normal walker (i.e., biological condition) and the split walker (i.e., less biological condition) as primes, separately depicted for the three different SOA conditions in Experiment 3. In this experiment, the letters L and $\mathrm{R}$ are used as targets. Error bars represent the standard error of the mean. ${ }^{* *} p \leq$ $0.001,{ }^{*} p \leq 0.05$

\section{Experiment 4}

Because Experiments 1 and 3 provided important insights into the compatibility effects in response priming with moving dot stimuli (additionally differing in their biological salience), using SOAs of up to $800 \mathrm{~ms}$, in Experiment 4 the focus was on compatibility effects with very long SOAs. One could suggest that the decrease of the compatibility effect at a SOA of $800 \mathrm{~ms}$ will continue and result in a sign change, that is, negative compatibility effects or negative compatibility effects with long SOAs, corresponding to the negative effects found using simple (nonbiological) motion primes (Bermeitinger, 2013) or the classic masked response priming experiments (Aron et al., 2003; Eimer, 1999; Eimer \& Schlaghecken, 1998, 2002, 2003; Jaśkowski, Jaśkowski, Bialunska, Tomanek, \& Verleger, 2008; Klauer \& Dittrich, 2010; Lleras $\&$ Enns, 2005). Thus, in Experiment 4, two very long SOAs of $920 \mathrm{~ms}$ and $1320 \mathrm{~ms}$ were used.

\section{Method}

Participants In Experiment 4, 41 students from the University of Hildesheim ( 36 women and 5 men) participated in exchange for money or course credit (age range 18 to 42 , $M d=21$ years). They were randomly assigned to one of the two SOA conditions. In the 920-ms SOA condition, 21 persons were tested. In the 1320-ms SOA condition, 20 persons were tested.

Design, Stimuli, Procedure We used the same design, stimuli, and procedure as for Experiment 1 with the following exceptions. First, the SOA was varied in two steps: 920 and $1320 \mathrm{~ms}$. Second, each slide of the prime-stimuli was presented for two refresh cycles each (i.e., approx. $27 \mathrm{~ms}$ ), resulting in an overall prime presentation duration of 240 ms. ${ }^{1}$ The blank display intervals following the prime were now 680 and $1080 \mathrm{~ms}$, for the 920- and 1320-ms SOA conditions, respectively.

\section{Results}

Mean error rate of all trials was 1.1\% (correlations showed that RT and error-rate effects went into the same direction or were not correlated, i.e., there was no speed-accuracy tradeoff). Reaction times were treated as in Experiment 1, resulting in $4.3 \%$ of all trials being discarded. Mean response times and errors are shown in Table 1.

A 2 (SOA: 920, $1320 \mathrm{~ms}) \times 2$ (biologicalness: biological, less biological) $\times 3$ (compatibility: compatible, incompatible, neutral) mixed ANOVA showed no influences of the factors biologicalness or SOA, $F_{\mathrm{S}}<1$, but yielded a main effect of compatibility, $F(2,78)=9.88, M S E=52.28, p \leq 0.001, \eta_{\mathrm{p}}{ }^{2}=$ 0.20 . Again, differences between the single conditions were tested by repeated contrasts. RTs were shorter in neutral than in incompatible trials, $F(1,39)=13.16, M S E=110.37, p \leq$ $0.001, \eta_{\mathrm{p}}^{2}=0.25$. No significant difference was found between compatible and neutral trials, $F<1$. This suggests that the compatibility effect is based on restriction of incompatible trials but not on facilitation due to preactivations from compatible primes.

Additionally, the two- and three-way interactions were nonsignificant, all $F_{\mathrm{S}}<1$. To test whether the compatibility effects in each SOA $x$ biologicalness condition were significant, we conducted separate $t$ tests.

Biological movement condition In biological trials, a small but positive compatibility effect occurred in both SOA conditions, SOA 920: $M=6 \mathrm{~ms}, S D=12.26, t(20)=2.07, p \leq 0.05$, SOA 1320: $M=4 \mathrm{~ms}, S D=8.03, t(19)=2.21, p \leq 0.05$ (Fig. 4).

Less biological movement condition The positive compatibility effect at the SOA of $920 \mathrm{~ms}$ was marginally significant, $M=4 \mathrm{~ms}, S D=10.47, t(20)=1.71, p \leq 0.10$, and the priming effect at the SOA of $1320 \mathrm{~ms}$ was significant, $M=4 \mathrm{~ms}, S D=$ $8.78, t(19)=2.28, p \leq 0.05$ (Fig. 4).

\section{Discussion}

Experiment 4 was designed to investigate compatibility effects with biologically moving stimuli in a response priming

\footnotetext{
${ }^{1}$ Actually, this was due to a programming error. However, earlier findings (e.g., Bermeitinger, 2013) showed that results did not depend on prime presentation duration. Thus, for the sake of convenience, we discussed the results just in terms of SOA. The points we discuss also will hold if we used the phrase "longer SOA and/or prime duration."
} 
paradigm with extremely long SOAs. It tested whether the compatibility effects found in Experiment 1 would sustain or whether preactivations would diminish to zero or even invert, resulting in negative compatibility effects as found with long SOAs in previous studies using moving dots as primes (Bermeitinger, 2013).

Despite the implementation of longer SOAs, we still found positive compatibility effects in both SOA conditions of Experiment 4. Thus, even with a long SOA of up to 1320 $\mathrm{ms}$, the prime stimulus had an influence on the target response, and there were faster reaction times for compatible than incompatible trials. In particular, the inhibiting effect of incompatible primes was still present with extremely long SOAs.

There were no differences between the two SOA conditions. Thus, regarding only Experiment 4, no clear time course (in terms of a linear rise or fall for compatibility effects depending on SOA) could be shown. Also, we found no differences for compatibility effects between biological and nonbiological trials. Compared with Experiment 1, the compatibility effects were much smaller, especially in biological trials, but quite similar to the effects found in the $800 \mathrm{~ms}$ condition of Experiment 1. In fact, in the biological movement condition, the effects of the 920 and 1320 SOA conditions seem to represent the continuation of the decline found in Experiment 1. In conclusion, Experiments 1 and 4 revealed a time course of the priming effect that is significantly different from what is most commonly found in classical response priming studies as well as response priming experiments using simple moving dots as primes (Bermeitinger, 2013). At no point of the SOA variations from short $(150 \mathrm{~ms})$ to long $(1320 \mathrm{~ms})$ did a negative effect occur.

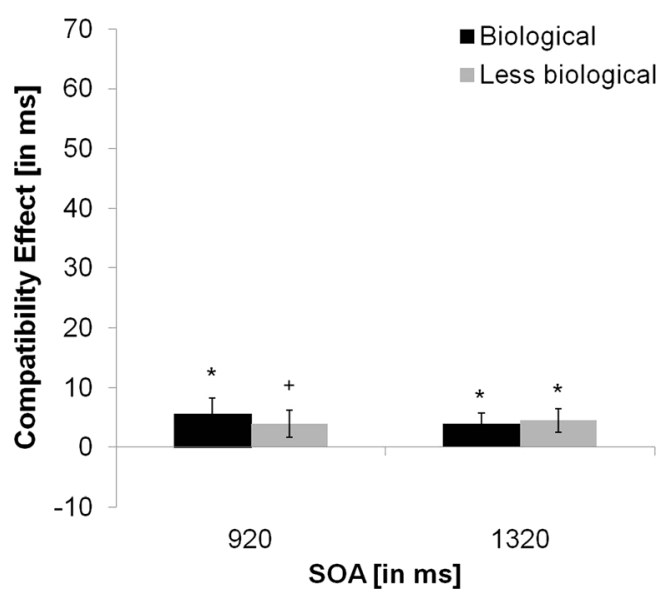

Fig. 4 Compatibility effects (in $\mathrm{ms}$ ). Differences in RTs between compatible and incompatible trials for trials using the normal walker (i.e., biological condition) and the split walker (i.e., less biological condition) as primes, separately depicted for the two different SOA conditions in Experiment 4. Error bars represent the standard error of the mean. ${ }^{*} p \leq 0.05,{ }^{+} p \leq 0.05$, one-tailed

\section{Experiment 5}

Because there is not yet a broad body of research for experiments comparable to the response priming setting using moving stimuli (with moving dots or biological motion), one could argue that the effects found in Experiments 1, 3, and 4 might be material-specific. There might be something special about the dot patterns of the point-light walker that is responsible for what we refer to as compatibility effects but does not apply to biological or other movements generally. Second, one might assume that motions of the whole body of a human being, as represented by point light walkers, might be rather unique, based inter alia on neurophysiological findings (Beauchamp, Lee, Haxby, \& Martin, 2003; Grossman \& Blake, 2002; Grossman et al., 2000; Vaina, Solomon, Chowdhury, Sinha, $\&$ Belliveau, 2001). Given the scarcity of research using biological motion, it would be desirable to use another kind of biological motion involving only some parts of the body. Third, although the larger compatibility effects with biological primes in Experiment 1 and 4 cannot be explained by enhanced discrimination of directionality of the biological stimuli (Experiment 2), we now disentangled explicitly the effects of static direction of the first picture of the point-light display sequences and the direction of the motion-also to make the material in this special point comparable to the row-of-dots primes used by Bermeitinger (2013), which always started with the same nondirectional row at the center of the screen. For these reasons, in Experiment 5 we used another set of biological and less biological stimuli, namely faces with moving gaze and moving dots, respectively. Schematic faces with moving irises and pupils were used to simulate a lateral gaze movement from a central position to the left or right, respectively. The materials allowed identical starting displays for both directions (right and left). Besides that, gaze and eye movements are important aspects of nonverbal communication in general and emotional expression in particular. Eye gaze stimuli are well known as valid stimuli for cueing attention (for review Frischen et al., 2007). Therefore, gaze movement is an essential aspect of social interaction and should be of high relevance for perceivers. Due to the different stimulus materials, we used slightly different presentation times and SOAs (i.e., 307 and $600 \mathrm{~ms}$ ) compared with Experiments 1 to 4 .

\section{Method}

Participants In Experiment 5, 35 students from the University of Hildesheim (32 women, 3 men) participated in exchange for partial course credits (age range 19-45, $M d=20$ years). They were randomly assigned to one of the two SOA conditions. In the $307-\mathrm{ms} \mathrm{SOA}$ condition, 18 persons were tested, and in the 600ms SOA condition, 19 persons were tested. 
Design A 2 (SOA: 307, $600 \mathrm{~ms}) \times 2$ (biologicalness: biological, less biological) $\times 3$ (compatibility: compatible, incompatible, neutral) design was used. Again, SOA was varied between participants; the other factors were varied trial-by-trial within participants. The prime stimulus now was either a part of a schematic face with moving irises (biological) or two moving dots that were nearly identical to the moving irises but without the schematic face surrounding them. For the neutral conditions, we now used upwards and downwards movements of the irises or dots, respectively. Because there were no reaction time differences between upwards and downwards neutral movements in all SOA $\mathrm{x}$ biologicalness conditions (all $p \mathrm{~s}>0.56$ ), we aggregate the upwards and downwards movements to "neutral compatibility."

Stimuli and Procedure Stimuli and procedure of Experiment 5 were similar to that of Experiment 4, with the following exceptions. First, as prime stimuli in the biological movement condition, schematic partial faces (colors: black, grey, light green, light pink) were used. Face images were line drawings spanning a segment of a human face from the forehead to the bridge of the nose. This effectively evoked the impression of a human face but not specific features like mood or attractiveness (Fig. 5). The height of the face stimuli was $7.6 \mathrm{~cm}\left(7.26^{\circ}\right.$ visual angle $)$ and the width was $20.5 \mathrm{~cm}\left(19.58^{\circ}\right.$ visual angle). The only moving parts of the prime stimulus were the round black irises (containing grey pupils with a radius of $2 \mathrm{~mm}$ in their center) in the center of each eye, with a radius of $6 \mathrm{~mm}$. The distance of the middle point of the irises was $8.0 \mathrm{~cm}\left(7.64^{\circ}\right.$ visual angle). The irises moved to one direction, leading to the impression of a gaze movement toward that direction. At the beginning of each trial, the irises were in the center of the eyes. With each of the eight motion steps (i.e., every second refresh cycle), each iris moved approx. $1.4 \mathrm{~mm}$ toward one side of the screen (either both irises left or both right), performing a total horizontal movement of approximately $1.1 \mathrm{~cm}$ of each iris.

Second, we used two neutral motion directions: irises moved either upwards or downwards, leading to the impression of an upwards or downwards gaze. Due to the elliptic shape of the eye, the vertical movement distances of the irises and pupils (approximately $0.4 \mathrm{~cm}$ ) were smaller than in the horizontal movement case.
Third, the less biological movement condition was realized by using two black dots (Fig. 5) that were moving horizontally (right and left) or vertically (upwards and downwards) in the same manner that the irises did. The dots were identical to the irises in the biological movement condition, just without the grey pupils inside and the schematic face surrounding them.

Fourth, all stimuli in Experiment 5 were presented on a white background. Fifth, due to the fact that we used two neutral motions (i.e., upward and downward) in both biologicalness conditions, there were 4 experimental blocks with 96 trials each (instead of 72 trials as in Experiments 1 and 2), and 1 practice block with 24 trials at the beginning. Fifth, the blank display intervals following the prime were now 67 and $360 \mathrm{~ms}$, for the 307- and 600-ms SOA conditions, respectively.

\section{Results}

Mean error rate was $1.9 \%$ of all trials (correlations showed, that RT and error rate effects went into the same direction or were not correlated). Reaction times were treated as in Experiment 1, resulting in $6.4 \%$ of all trials being discarded. Mean response times and errors are shown in Table 1.

The mixed 2 (SOA) x 2 (biologicalness) x 3 (compatibility) ANOVA revealed a significant main effect of SOA, $F(1,33)=$ 5.53, MSE $=1458.27, p \leq 0.05, \eta_{\mathrm{p}}{ }^{2}=0.14$, indicating overall faster reactions with the longer SOA. Additionally, the factor biologicalness had a significant influence on reaction times, $F(1,33)=5.76, M S E=117.01, \eta_{\mathrm{p}}{ }^{2}=0.15, p \leq 0.05$, indicating faster reactions in biological (i.e., gaze) trials than less biological (i.e., dots) trials. Furthermore, there was a significant main effect of prime-target compatibility, $F(1,57,51.81)=72.92, M S E=$ $171.46, p \leq 0.001, \eta_{\mathrm{p}}{ }^{2}=0.69$. Repeated contrasts revealed faster RTs for compatible than neutral trials, $F(1,33)=66.28, M S E=$ 209.06, $p \leq 0.001, \eta_{\mathrm{p}}{ }^{2}=0.67$, and faster RTs for neutral than incompatible trials, $F(1,33)=33.17, M S E=188.90, p \leq 0.001$, $\eta_{\mathrm{p}}{ }^{2}=0.50$. Overall, there was a general positive compatibility effect, with faster reactions when the movement's direction and the arrow's direction were identical. This positive compatibility effect again comprised a facilitating effect of compatible primes (faster RTs in compatible than neutral trials) and a restricting effect of incompatible primes (slower RTs in incompatible than neutral trials). Again, significant interactions were found between

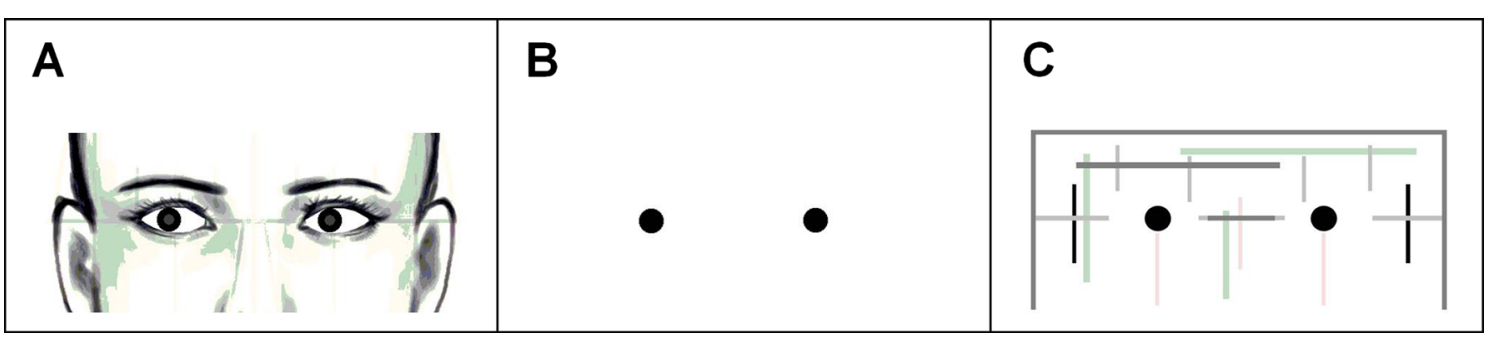

Fig. 5 Examples of one slide of the motion materials used for the primes in Experiment 5 and 6. (a) One display of the biological condition in Experiment 5 and 6, i.e., the schematic face (looking toward the left). (b) One display from the less biological condition in Experiment 5, i.e., simple dots. (c) One display from the less biological condition in Experiment 6, i.e., dots embedded in a geometrical line drawing 
the factors compatibility and SOA, $F(1.57,51.81)=36.89, M S E$ $=171.46, p \leq 0.001, \eta_{\mathrm{p}}{ }^{2}=0.53$, between the factors biologicalness and compatibility, $F(1.72,56.59)=14.72, M S E$ $=51.45, p \leq 0.001, \eta_{\mathrm{p}}{ }^{2}=0.31$, and between all three factors, $F(1.72,56.59)=4.35, M S E=51.45, p \leq 0.05, \eta_{\mathrm{p}}{ }^{2}=0.12$. As before, separate ANOVAs and $t$ tests were conducted for biological and less biological conditions.

Biological movement condition The mixed 2 (SOA) x 3 (compatibility) ANOVA showed a significant effect of the SOA, $F(1,33)=5.42, M S E=843.46, p \leq 0.05, \eta_{\mathrm{p}}{ }^{2}=0.14$, indicating overall faster reaction in the $600 \mathrm{~ms}$ SOA condition than in the $300 \mathrm{~ms}$ SOA condition. Furthermore, there was a significant main effect of compatibility, $F(1.52,50.25)=73.66$, $M S E=135.50, p \leq 0.001, \eta_{\mathrm{p}}{ }^{2}=0.69$. Additionally, a significant interaction between prime-target compatibility and SOA was found, $F(1.52,50.25)=29.83, M S E=135.50, p \leq 0.001, \eta_{\mathrm{p}}{ }^{2}$ $=0.48$, indicating that the size of the compatibility effect in gaze trials depended on the SOA between prime and target stimuli.

One-sample $t$ tests (comparing to zero) revealed a significant compatibility effect for the $307 \mathrm{~ms}$ SOA condition, $M=$ $47 \mathrm{~ms}, S D=15.55, t(17)=12.75, p \leq 0.001$, as well as a smaller (significant interaction, see above) but still clearly significant compatibility effect for the 600-ms SOA condition, $M=11 \mathrm{~ms}, S D=19.90, t(16)=2.33, p \leq 0.05$ (Fig. 6).

Less biological movement condition The analogue ANOVA for the trials containing dots as prime stimuli also showed a significant main effect of SOA, $F(1,33)=5.39, M S E=$ 653.82, $p \leq 0.05, \eta_{\mathrm{p}}{ }^{2}=0.14$, indicating again overall faster reactions in the $600-\mathrm{ms}$ SOA condition. The main effect of compatibility also reached significance, $F(1.68,55.51)=$ $37.92, M S E=89.83, p \leq 0.001, \eta_{\mathrm{p}}{ }^{2}=0.54$. The interaction between compatibility and SOA was significant as well, $F(1.68,55.51)=27.54, M S E=89.83, p \leq 0.001, \eta_{\mathrm{p}}{ }^{2}=0.46$, indicating different compatibility effects depending on SOA.

Subsequent one-sample $t$ tests (compared to zero) showed that a compatibility effect occurred only in the 307-ms SOA condition, $M=34 \mathrm{~ms}, S D=10.65, t(17)=13.36, p \leq 0.001$, but not in the $600-\mathrm{ms}$ SOA condition, $M=3 \mathrm{~ms}, S D=17.76, t$ $<1, p=0.54$ (Fig. 6).

\section{Discussion}

In Experiment 5, we found positive compatibility effects with moving dots as primes on target arrows: dots turning to one side facilitated the classification of an arrow pointing in the same direction, in contrast to dots turning to the other side or a neutral gaze movement. Again, there was no evidence for negative compatibility effects. Additionally, we found differences in priming effects between biological and less biological motion primes, similar to those found in Experiments 1 and 3. Dots that were embedded in a schematic face picture (i.e., biological), that is, the

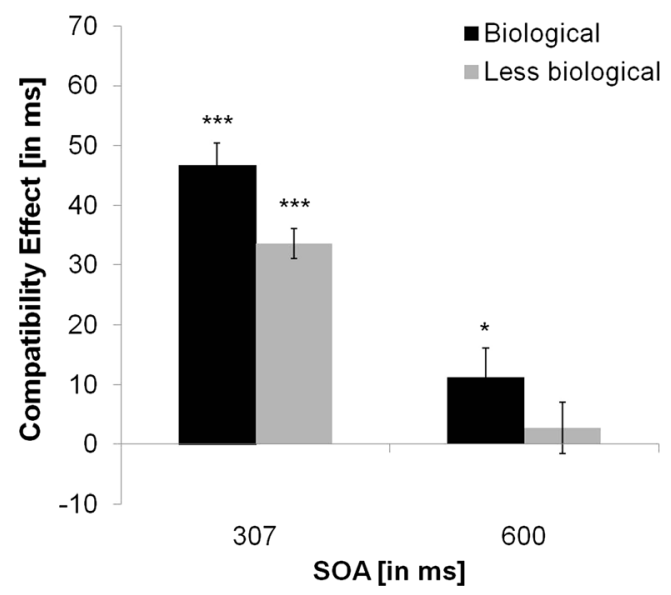

Fig. 6 Compatibility effects (in ms). Differences in RTs between compatible and incompatible trials for trials using schematic faces with moving irises (i.e., biological condition) and simple moving dots (i.e., less biological) as primes, separately depicted for the two different SOA conditions in Experiment 5. Error bars represent the standard error of the mean. ${ }^{* * *} p \leq 0.001,{ }^{*} p \leq 0.05$

dots can be interpreted as moving irises, produced larger compatibility effects than the same two dots not embedded into a face (i.e., less biological). Interestingly, the less biological condition in Experiment 5 with two simple dots shifted horizontally toward the right or left is comparatively similar to the row-of-dots primes in Bermeitinger (2013) with 11 dots. At least with the long SOA of $600 \mathrm{~ms}$ in Experiment 5, one could have expected to find negative compatibility effects, as was found with the row-ofdots primes. Overall, we could interpret this as tentative evidence that the special material used in Bermeitinger (2013) led to the positive-followed-by-negative-compatibility effects pattern therein. However, when comparing the biological and less biological condition in Experiment 5, one might question whether they are comparable regarding other features except their biological salience.

\section{Experiment 6}

Experiment 5 showed clear differences in the compatibility effects between moving dots embedded into a schematic face and interpreted as moving gaze (i.e., biological movement condition) and moving dots without the surrounding of a schematic face (i.e., less biological condition). However, one might argue that the difference between the stimuli used in Experiment 5 is not (solely) their degree of biological salience. Instead, they also differed regarding their reference frames or references points: the less biological stimuli were moving on a blank screen with no other reference provided, whereas the biological stimuli provided clear references - the moving elements (irises) are surrounded by many stationary elements (e.g., eyebrows, nose, and ears). Facing the fact that the visually perceived spatial relation between an object and a reference as well as background 
information are crucial elements of detecting motion (Leibowitz, 1955), the absence of such a reference or background will reduce its salience and might impair motion perception per se. This factor might have contributed to the difference between the compatibility effects for the biological and less biological movement in Experiment 5. To test this assumption for the less biological condition, we created geometric arrangements of various vertical and horizontal lines surrounding the dots, serving as a stationary spatial reference. Thereby, the references provided by the prime stimuli in the biological and less biological conditions became similar.

\section{Method}

Participants In Experiment 6, 54 students from the University of Hildesheim (45 women, 9 men) participated, in exchange for partial course credits (age range 19-28, $M d=21$ years). They were randomly assigned to one of the two SOA conditions. In the 307-ms SOA condition, 26 persons were tested. In the $600-\mathrm{ms}$ SOA condition, 28 persons were tested.

Design, Stimuli, Procedure The same stimuli and procedure as in Experiment 5 were used, with the exceptions that we designed new stimuli for the less biological movement condition. For the less biological primes, we used two dots (identical to those in Experiment 5) surrounded by a geometric arrangement of various horizontal and vertical lines (Fig. 5). The same colors as those of the schematic face were used for the lines, and the luminance of both stimuli was similar. Additionally, the sizes of both prime stimuli were the same. The movement of the dots was identical to Experiment 5. As in Experiment 5, there were no reaction time differences between upwards and downwards neutral movements in all SOA $x$ movement conditions (all $p \mathrm{~s}>$ 0.21). Thus, we again aggregate the upwards and downwards movements to "neutral compatibility."

\section{Results}

Mean error rate was $3.5 \%$ of all trials (correlations showed that RT and error rate effects went into the same direction or were not correlated). Reaction times were treated as in Experiment 1, resulting in $4.6 \%$ of all trials being discarded. Mean response times and errors are shown in Table 1.

The mixed 2 (SOA) x 2 (biologicalness) x 3 (compatibility) ANOVA showed a significant main effect of SOA, $F(1,52)=$ $13.77, M S E=1437.01, p<0.01, \eta_{p}{ }^{2}=0.21$, indicating again faster overall responses in the $600 \mathrm{~ms}$ SOA condition compared to the 307-ms SOA condition. Furthermore, the main effect of biologicalness condition was significant, $F(1,52)=21.67, M S E$ $=61.34, p<0.001, \eta_{\mathrm{p}}{ }^{2}=0.29$, indicating overall slightly slower responses to biological primes. Importantly, a significant main effect of prime-target compatibility was found, $F(1.32,68.61)=$ $53.25, M S E=313.70, p<0.001, \eta_{\mathrm{p}}{ }^{2}=0.51$. Repeated contrasts revealed faster RTs for compatible than neutral trials, $F(1,52)=$ $59.31, M S E=528.61, p<0.001, \eta_{\mathrm{p}}{ }^{2}=0.53$, and faster RTs for neutral than incompatible trials $(F(1,52)=61.72, M S E=264.80$, $\left.p<0.001, \eta_{\mathrm{p}}{ }^{2}=0.54\right)$. Again, there was a general positive compatibility effect, with faster reactions when the movement's direction and the arrow's direction were identical. This positive compatibility effect again comprised a facilitating effect of compatible primes (faster RTs for compatible than neutral trials) and a restricting effect of incompatible primes (slower RTs for incompatible than neutral trials).

Furthermore, there were significant interactions between compatibility and SOA, $F(1.32,68.61)=53.25, M S E=475.51, p<$ $0.001, \eta_{\mathrm{p}}{ }^{2}=0.54$, between biologicalness and SOA, $F(1,52)=$ $7.48, M S E=81.48, p<0.01, \eta_{\mathrm{p}}{ }^{2}=0.13$, between compatibility and biologicalness, $F(1.76,91.25)=12.87, M S E=81.48, p<$ $0.001, \eta_{\mathrm{p}}{ }^{2}=0.20$, and between compatibility, biologicalness, and SOA, $F(1.76,91.25)=5.38, M S E=81.48, p<0.01, \eta_{\mathrm{p}}{ }^{2}=0.09$. Separate ANOVAs and $t$ tests were conducted for biological and less biological conditions.

Biological movement condition The mixed 2 (SOA) x 3 (compatibility) ANOVA showed a significant effect of the SOA, $F(1,52)=15.28, M S E=22321,99, p<0.001, \eta_{\mathrm{p}}{ }^{2}=$ 0.23 , indicating overall faster reaction in the $600-\mathrm{ms}$ SOA condition than the 300-ms SOA condition. There was a significant main effect of compatibility, $F(1.37,71.22)=60.36, M S E=$ $307.30, p<0.001, \eta_{\mathrm{p}}{ }^{2}=0.54$. Additionally, a significant interaction between prime-target compatibility and SOA was found, $F(1.37,71.22)=59.79, M S E=307.30, p<0.001, \eta_{\mathrm{p}}{ }^{2}=0.54$, indicating that the size of the compatibility effect in biological trials depended on the SOA between prime and target stimuli.

One-sample $t$ tests (comparing to zero) revealed a significant compatibility effect for the 307-ms SOA condition, $M=$ $60 \mathrm{~ms}, S D=29.08, t(27)=10.85, p<0.001$, but-and in contrast to Experiment 5-no compatibility effect in the 600-ms SOA condition, $M=0 \mathrm{~ms}, S D=23.47, t \leq 1$ (Fig. 7).

Less biological movement condition With the geometrical reference frame surrounding the dots, the analogue ANOVA yielded a significant main effect of SOA, $F(1,52)=12.14$, $M S E=1433.31, p<0.01, \eta_{\mathrm{p}}{ }^{2}=0.19$, as well as compatibility $\left(F(1.41,73.44)=28.18, M S E=247.46, p<0.001, \eta_{\mathrm{p}}{ }^{2}=0.35\right.$. The interaction of both factors also was significant, $F(1.41$, $73.44)=40.88, M S E=247.46, p<0.001, \eta_{\mathrm{p}}{ }^{2}=0.44$, again indicating that the size of the compatibility effect differed significantly between SOA levels.

Subsequent one-sample $t$ tests (comparing to zero) showed a significant compatibility effect in the $307-\mathrm{ms}$ SOA condition, $M$ $=41 \mathrm{~ms}, S D=29.34, t(27)=7.36, p<0.001$, but not in the 600 ms condition, $M=-4 \mathrm{~ms}, S D=14.59, t(25)=1.47, p=0.16$ (Fig. 7). 


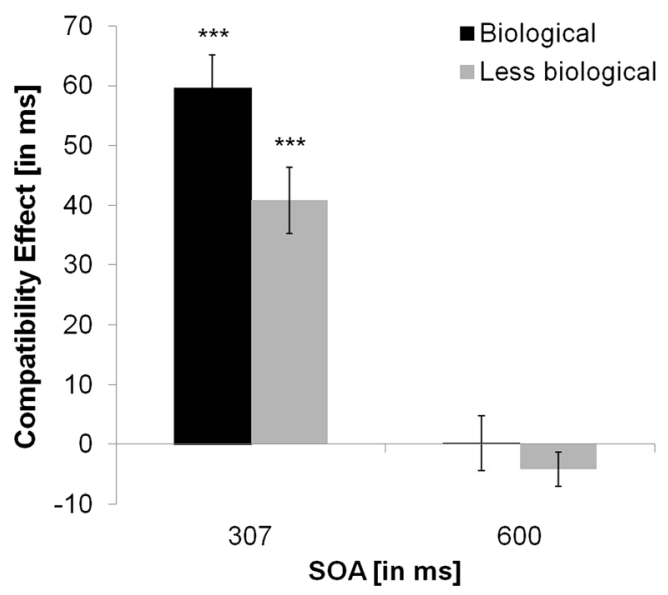

Fig. 7 Compatibility effects (in ms). Differences in RTs between compatible and incompatible trials for trials using schematic faces with moving irises (i.e., biological condition) and moving dots embedded in geometrical line drawings (i.e., less biological) as primes, separately depicted for the two different SOA conditions in Experiment 6. Error bars represent the standard error of the mean. ${ }^{* * *} p \leq 0.001$

\section{Discussion}

In Experiment 6, we again used schematic eye gaze stimuli as biological primes but used a geometric arrangement of various vertical and horizontal lines surrounding the dots, serving as a stationary spatial reference, as less biological prime stimuli. The references provided by the prime stimuli in the biological and less biological conditions became similar. First, the patterns found in Experiment 5 and Experiment 6 were highly similar. Again, we found larger compatibility effects in the shorter SOA and no condition significant negative compatibility effects. Additionally, we found larger compatibility effects with biological than less biological motion primes. If the differences for compatibility effects between the biological (i.e., gaze) and less biological (i.e., simple dots) conditions in Experiment 5 would have been caused by differences in reference frames, then we would have expected no differences between the compatibility effects with biological and less biological primes in Experiment 6. However, such differences were clearly present and of a very similar magnitude to Experiment 5. We interpret this as evidence that differences for compatibility effects between biological and less biological motion conditions are not caused by differences in the degree of reference. Instead, differences for compatibility effects could be attributed to differences in biological salience.

\section{General Discussion}

The present research was conducted to investigate the influence of (biologically) moving stimuli on response activation. More specifically, we tested several moving dot stimuli as primes for static arrow targets in a response priming paradigm to investigate the influence of the special kind of moving dots on the positive-followed-by-negative-compatibility effects pattern (with SOAs from 50-500 ms) found by Bermeitinger (2013) using moving lines of 11 dots. In the present study, we used the response priming paradigm with a similar procedure as used in Bermeitinger (2013) but with several other motion types. To broaden our research focus, we additionally investigated different biological and less biological dot motions, also to test whether response priming in the narrow sense could be a useful tool to study the processing of visually perceived biological motions. For our experiments, we created pointlight displays either of a human normal walker versus a split walker (Experiments 1 to 4 ) and dots embedded in a schematic face representing the irises versus either simply two dots (Experiment 5) or two dots embedded in an abstract line drawing (Experiments 6). Furthermore, we varied the SOA between prime and target onset; there were SOAs of 147, 307, $360,600,800,920$, and $1320 \mathrm{~ms}$. Overall, we found no evidence for negative compatibility effects, even with the largest SOA of $1320 \mathrm{~ms}$ (Experiment 4) nor with biological or less biological motion types. Additionally, we found overall larger compatibility effects with biological motion primes than with less biological motion primes. With longer SOAs, these differences vanished (especially in Experiment 4). The differences between compatibility effects with biological versus less biological primes cannot be attributed to differences in the degree of directionality (see Experiment 2), differences due to the fact that the first display of the biological motion primes comprises more information of directionality than the first display of the less biological motion primes (see Experiments 5 and 6), or simply due to the fact that the discrimination of arrow targets is easier when attention is shifted toward the arrow's tip (see Experiment 3 with letter targets).

Two aspects about the general pattern of compatibility results seem especially noteworthy: First, the current compatibility effects the coherent, normal point-light walkers of more than $40 \mathrm{~ms}$ are very strong and pronounced, particularly compared with recent studies on response priming using other nonbiological motions (Bermeitinger, 2013; but see Mattler \& Fendrich, 2007, who used rotating dots as primes and found compatibility effects of approximately $70 \mathrm{~ms}$ with an SOA of $119 \mathrm{~ms}$ ). Second, based on the findings of Bermeitinger (2013), who reported negative compatibility effects with SOAs above 200 $\mathrm{ms}$, one could have expected negative compatibility effects in conditions with longer SOAs. Actually, no such negative effects emerged, not even in the longest SOA tested $(1320 \mathrm{~ms}$ in Experiment 4). However, in Experiment 6, numerically a negative compatibility effect with less biological motion stimuli and no compatibility effect with biological motion stimuli were found in the longer SOA. Future research is needed to clarify whether there is really a turn into negative compatibility effects with longer SOAs using the materials of Experiment 6. 
Interestingly, the dots used in Experiments 5 and 6 are similar to the materials used by Bermeitinger (2013) in several aspects. Bermeitinger used rows of 11 dots, which moved to the right or left. At short SOAs (100 and $150 \mathrm{~ms}$ ), she reported positive compatibility effects, but negative compatibility effects emerged at longer SOAs (between 250 and $500 \mathrm{~ms}$ ). In the current Experiments 5 and 6 with nonbiological primes, there were clearly no negative compatibility effects, neither in the $307-\mathrm{ms}$ nor the $600-\mathrm{ms}$ SOA conditions. At this point, we can just speculate what the reasons for this difference might be. Possibly, the rows of 11 dots were more salient and might have triggered response tendencies faster than rows with only 2 dots. In consequence, fast-acting counterregulative mechanisms may have come into play to curtail the unwarranted overreaction (Schlaghecken \& Eimer, 2002). With only 2 dots, the initial activation might be less pronounced, obviating the need for quick and pronounced counterregulation. For now, we have to conclude that the stable pattern of positivefollowed-by-negative-compatibility effects highly depends on material and specific motion. Furthermore, negative compatibility effects did not occur with biological motion primes.

Looking at the novel factor in the current experiment - the biological salience of the prime stimulus - we found overall larger compatibility effects with biological than less biological primes. This suggests that apparent coherent biological movements entail activation or orient attention, possibly connected to motor preparation for incoming stimuli. In terms of more specific, compatibility-driven effects, positive compatibility effects were particularly strong in intact biological movement trials. This suggests that an action performed by an intact biologically moving stimulus like a point-light walker is a very salient indicator of a specific direction (presumably more salient than moving dots, Bermeitinger, 2013, or geometrical static stimuli, e.g., Schmidt et al., 2011) and thus leads to a stronger initial activation of the motor response corresponding to the direction of the prime. The strong effects of biological stimuli might be due to the fact that biological movements in the environment have a great potency to prepare or trigger own actions.

In terms of global and local mechanisms of biological motion perception, the global shape of the normal walker was disrupted in the split walker, but it (1) still contained a partly global shape - that is, the configuration of an upper and lower part of a body were almost intact (but put differently together than in the normal walkers) - and (2) there were the same local dot movements as in the normal walkers, and they have been found to carry directional information as well (Chang \& Troje, 2009a; 2009b; Wang et al., 2014). Therefore, the diminution of biological salience, which eventually seems inseparably connected to the factor of "global shape disruption," was presumably the crucial factor to explain the differences for compatibility effects.

A clear dependency on the SOA emerged in terms of a decreasing compatibility effect with the longer SOAs, also with biological motion primes. Based on the dependency on the SOA, one could assume that the activation of one response by intact biologically moving stimuli is a phenomenon that occurs very quickly and gradually gets weaker. This notion meshes well with assumptions regarding the importance of quick perception of biological movements. Perceiving another living being can be seen as the prerequisite for reacting appropriately. Once a biological motion is detected, further processing needs to orient attention and prepare a response (mostly motor reactions like hunting, escaping, or approaching, in terms of an evolutionary perspective) quickly. Thus, there is a benefit for the organism if the visuomotor and the attention orienting effects of biological motion perception arise very quickly. Various suggestions could be made regarding the decline of the compatibility effect in normal walker trials with increasing SOA. Perhaps some kind of control mechanism detects differences between a relevant biological motion and an irrelevant biological motion and thus partly inhibits the initial strong activation in case of an irrelevant movement.

Facing the aspect of action preparation in particular, contemporary theories assume that perception and action are coded in the same representational code (Hommel et al., 2001). Perceived biological motion might have a particular impact, because people do not only perceive biological movements, they also make biological movements (Winkielman, McIntosh, \& Oberman, 2009, for a similar argument regarding faces). Additionally, biologically moving objects in the environment have a special (evolutionary) meaning, either as prey, predator, or conspecific and, for humans most importantly, as a potential opportunity for social interaction (Jokisch \& Troje, 2003). In fact, perception of biological movements often is seen as an instance of social perception (Adolphs, 2001; Allison, Puce, \& McCarthy, 2000). Hence, extracting information from a visual impression is very important (Blake \& Shiffrar, 2007). Keeping in mind that even one's own life can depend on how quickly the actions of other human beings and animals are interpreted, biologically moving elements have to be processed in a manner that quickly guides attention and prepares actions. One crucial feature of a movement is its direction. Hence, the present findings of strong compatibility effects in biological trials using short SOAs can be explained easily by fast processes of action activation. The generally smaller compatibility effects with primes of a lower biological salience fit into this explanation when we assume that they trigger attention orienting and motor responses less quickly and with lower intensity than biological stimuli of high biological salience.

Our results corroborate the notion that biological movements are processed in a special way and play a key role in action activation. Apart from the differences to nonbiological movements (see above), the compatibility effects with point-light walkers and gaze movements are comparable. Both motion types led to positive compatibility effects of similar magnitude at the 
most comparable SOA (Experiment 1 with point-light walkers: $360 \mathrm{~ms}$, Experiment 3 with faces: $307 \mathrm{~ms}$ ). This seems especially noteworthy, because there is evidence for specific brain regions that are active when subjects either view a face with moving eyes or mouth (i.e., the posterior portion of the straight segment of the superior temporal sulcus, STS, which is not active when motion other than biological was performed; Puce, Allison, Bentin, Gore, \& McCarthy, 1998) or view moving point-light displays (i.e., lateral and inferior temporal cortex and regions in the inferior frontal cortex; Saygin et al., 2004). These authors suggested that by activating frontal areas of the human brain, moving stimuli can recruit action observation networks. One question for future work might be whether the compatibility effects with different (biological) primes are the result of common or different mechanisms or areas in the perceptuomotor network.

In summary, our results showed positive compatibility effects in almost all conditions (and no evidence for negative priming), whereas compatibility effects with biological primes were considerably larger than compatibility effects with less biological primes, in particular with short SOAs.

In conclusion, the response priming paradigm, which has several advantages over simpler motion response paradigms, seems to be a suitable tool for further investigating motion in general and comparing different motion types. The pattern of positive compatibility effects with shorter SOAs and negative compatibility effects with longer SOAs found by Bermeitinger (2013) seems to be specific for the motion and material used therein but does not appear generally with motion primes.

Acknowledgments The authors thank Wilfried Kunde and Thomas Schmidt for helpful comments in relation to the present research. Many sincere thanks go to Ryan Hackländer and Ulli Ecker for improving the readability of the article and encouraging significant improvements of it in general. Additionally, the authors thank Patrick Jähne and Alexander Dockhorn for technical assistance.

\section{Appendix}

Table 2 2-D coordinates (X and $\mathrm{Y}$ ) for the (A) left and (B) right walker used as biological material in Experiment 1, 2, 3, and 4. The point of origin is located at the upper left corner of each image. Each row represents one $\operatorname{dot}(1=$ head, $2-3=$ shoulders, $4-5=$ elbows, $6-7=$ wrists,
$8=$ abdomen, $9-10=$ hips, $11-12=$ knees, $13-14=$ ankles). $\mathrm{X} 1 / \mathrm{Y} 1$ give the spatial coordinates of the markers in the first frame, $\mathrm{X} 2 / \mathrm{Y} 2$ give the coordinates for the second frame, and so on

\begin{tabular}{|c|c|c|c|c|c|c|c|c|c|c|c|c|c|c|c|c|c|c|}
\hline dot & $\mathrm{X} 1$ & $\mathrm{Y} 1$ & $\mathrm{X} 2$ & Y2 & X3 & Y3 & $\mathrm{X} 4$ & Y4 & X5 & Y5 & X6 & Y6 & $\mathrm{X} 7$ & Y7 & X8 & Y8 & X9 & Y9 \\
\hline \multicolumn{19}{|l|}{ (A) } \\
\hline 1 & 253 & 69 & 253 & 71 & 253 & 71 & 254 & 72 & 255 & 72 & 256 & 72 & 256 & 71 & 255 & 70 & 255 & 69 \\
\hline 2 & 246 & 83 & 247 & 85 & 247 & 85 & 248 & 84 & 249 & 84 & 250 & 84 & 250 & 84 & 250 & 83 & 252 & 82 \\
\hline 3 & 253 & 97 & 253 & 98 & 254 & 98 & 255 & 99 & 255 & 99 & 255 & 99 & 254 & 98 & 252 & 97 & 252 & 96 \\
\hline 4 & 239 & 101 & 239 & 102 & 240 & 102 & 242 & 102 & 244 & 102 & 246 & 102 & 249 & 102 & 251 & 102 & 254 & 102 \\
\hline 5 & 269 & 110 & 271 & 110 & 273 & 110 & 274 & 111 & 274 & 111 & 273 & 111 & 270 & 111 & 267 & 112 & 264 & 111 \\
\hline 6 & 199 & 106 & 200 & 104 & 200 & 103 & 203 & 103 & 205 & 104 & 207 & 106 & 210 & 110 & 213 & 113 & 218 & 118 \\
\hline 7 & 270 & 139 & 275 & 140 & 279 & 139 & 280 & 140 & 280 & 140 & 277 & 140 & 272 & 141 & 265 & 141 & 257 & 140 \\
\hline 8 & 250 & 124 & 250 & 125 & 250 & 126 & 250 & 126 & 250 & 126 & 251 & 126 & 250 & 125 & 250 & 124 & 250 & 123 \\
\hline 9 & 251 & 132 & 252 & 132 & 252 & 133 & 252 & 134 & 252 & 134 & 252 & 133 & 252 & 133 & 252 & 132 & 251 & 130 \\
\hline 10 & 245 & 134 & 245 & 135 & 245 & 136 & 245 & 136 & 245 & 136 & 245 & 136 & 245 & 135 & 245 & 134 & 246 & 133 \\
\hline 11 & 222 & 169 & 222 & 170 & 226 & 171 & 227 & 172 & 227 & 172 & 229 & 172 & 232 & 172 & 236 & 172 & 241 & 171 \\
\hline 12 & 268 & 169 & 271 & 170 & 273 & 170 & 273 & 171 & 271 & 172 & 266 & 172 & 261 & 172 & 255 & 171 & 250 & 169 \\
\hline 13 & 190 & 206 & 190 & 207 & 195 & 210 & 201 & 214 & 209 & 217 & 217 & 218 & 225 & 218 & 231 & 218 & 238 & 217 \\
\hline 14 & 292 & 211 & 299 & 210 & 306 & 208 & 312 & 206 & 317 & 204 & 317 & 201 & 313 & 199 & 304 & 199 & 295 & 202 \\
\hline \multicolumn{19}{|l|}{ (B) } \\
\hline 1 & 227 & 69 & 227 & 71 & 227 & 71 & 226 & 72 & 225 & 72 & 224 & 72 & 224 & 71 & 225 & 70 & 225 & 69 \\
\hline 2 & 234 & 83 & 233 & 85 & 233 & 85 & 232 & 84 & 231 & 84 & 230 & 84 & 230 & 84 & 230 & 83 & 228 & 82 \\
\hline 3 & 227 & 97 & 227 & 98 & 226 & 98 & 225 & 99 & 225 & 99 & 225 & 99 & 226 & 98 & 228 & 97 & 228 & 96 \\
\hline 4 & 241 & 101 & 241 & 102 & 240 & 102 & 238 & 102 & 236 & 102 & 234 & 102 & 231 & 102 & 229 & 102 & 226 & 102 \\
\hline 5 & 211 & 110 & 209 & 110 & 207 & 110 & 206 & 111 & 206 & 111 & 207 & 111 & 210 & 111 & 213 & 112 & 216 & 111 \\
\hline 6 & 281 & 106 & 280 & 104 & 280 & 103 & 277 & 103 & 275 & 104 & 273 & 106 & 270 & 110 & 267 & 113 & 262 & 118 \\
\hline 7 & 210 & 139 & 205 & 140 & 201 & 139 & 200 & 140 & 200 & 140 & 203 & 140 & 208 & 141 & 215 & 141 & 223 & 140 \\
\hline 8 & 230 & 124 & 230 & 125 & 230 & 126 & 230 & 126 & 230 & 126 & 229 & 126 & 230 & 125 & 230 & 124 & 230 & 123 \\
\hline 9 & 229 & 132 & 228 & 132 & 228 & 133 & 228 & 134 & 228 & 134 & 228 & 133 & 228 & 133 & 228 & 132 & 229 & 130 \\
\hline 10 & 235 & 134 & 235 & 135 & 235 & 136 & 235 & 136 & 235 & 136 & 235 & 136 & 235 & 135 & 235 & 134 & 234 & 133 \\
\hline 11 & 258 & 169 & 258 & 170 & 254 & 171 & 253 & 172 & 253 & 172 & 251 & 172 & 248 & 172 & 244 & 172 & 239 & 171 \\
\hline 12 & 212 & 169 & 209 & 170 & 207 & 170 & 207 & 171 & 209 & 172 & 214 & 172 & 219 & 172 & 225 & 171 & 230 & 169 \\
\hline 13 & 290 & 206 & 290 & 207 & 285 & 210 & 279 & 214 & 271 & 217 & 263 & 218 & 255 & 218 & 249 & 218 & 242 & 217 \\
\hline 14 & 188 & 211 & 181 & 210 & 174 & 208 & 168 & 206 & 163 & 204 & 163 & 201 & 167 & 199 & 176 & 199 & 185 & 202 \\
\hline
\end{tabular}




\section{References}

Adolphs, R. (2001). The neurobiology of social cognition. Current Opinion in Neurobiology, 11, 231-239.

Allison, T., Puce, A., \& McCarthy, G. (2000). Social perception from visual cues: Role of the STS region. Trends in Cognitive Sciences, 7, 267-278

Aron, A. R., Schlaghecken, F., Fletcher, P. C., Bullmore, E. T., Eimer, M., Barker, R., ... Robbins, T. W. (2003). Inhibition of subliminally primed responses is mediated by the caudate and thalamus: Evidence from functional MRI and Huntington's disease. Brain, 126, 713-723.

Beauchamp, M. S., Lee, K. E., Haxby, J. V., \& Martin, A. (2003). Parallel visual motion processing streams for manipulable objects and human movements. Neuron, 34, 149-159.

Beintema, J. A., \& Lappe, M. (2002). Perception of biological motion without local image motion. Proceedings of the National Academy of Sciences, 99, 5661-5663.

Bermeitinger, C. (2013). Response priming with apparent motion primes. Psychological Research, 77, 371-387.

Bertenthal, B. I., \& Pinto, J. (1994). Global processing of biological motions. Psychological Science, 5, 221-225.

Blake, R., \& Shiffrar, M. (2007). Perception of human motion. Annual Review of Psychology, 58, 47-73.

Bosbach, S., Prinz, W., \& Kerzel, D. (2004). A Simon-effect with stationary moving stimuli. Journal of Experimental Psychology: Human Perception and Performance, 30, 39-55.

Bosbach, S., Prinz, W., \& Kerzel, D. (2005). Is direction position? Position- and direction-based correspondence effects in tasks with moving stimuli. The Quarterly Journal of Experimental Psychology. Section A: Human Psychology, 58A, 467-506.

Calvo-Merino, B., Glaser, D. E., Grèzes, J., Passingham, R. E., \& Haggard, P. (2005). Action observation and acquired motor skills: An fMRI study with expert dancers. Cerebral Cortex, 15, 12431249.

Chang, D. H. F., \& Troje, N. F. (2008). Perception of animacy and direction from local biological motion signals? Journal of Vision, $8,3$.

Chang, D. H. F., \& Troje, N. F. (2009a). Acceleration carries the local inversion effect in biological motion perception. Journal of Vision, 9, 1-17.

Chang, D. H. F., \& Troje, N. F. (2009b). Characterizing global and local mechanisms in biological motion perception. Journal of Vision, 9, $1-10$.

Chemero, A. (2006). Radical embodied cognitive science. Cambridge: MIT Press.

Cross, E. S., Kraemer, D. J. M., de Hamilton, A. F., Kelley, W. M., \& Grafton, S. T. (2009). Sensitivity of the action observation network to physical and observational learning. Cerebral Cortex, 19, 415326

Decety, J., \& Grèzes, J. (1999). Neural mechanisms subserving the perception of human actions. Trends in Cognitive Sciences, 3, 172-178.

Di Pellegrino, G., Fadiga, L., Fogassi, L., Gallese, V., \& Rizzolatti, G. (1992). Understanding motor events: A neurophysiological study. Experimental Brain Research, 91, 176-180.

Dittrich, W. H., Troscianko, T., Lea, S. G. D., \& Morgan, D. (1996). Perception of emotion from dynamic point-light displays represented in dance. Perception, 25, 727-738.

Egeth, H. E., \& Yantis, S. (1997). Visual attention: Control, representation, and time course. Annual Review of Psychology, 48, 269-297.

Eimer, M. (1999). Facilitory and inhibitory effects of masked prime stimuli on motor activation and behavioral performance. Acta Psychologica, 101, 293-313.

Eimer, M., \& Schlaghecken, F. (1998). Effects of masked stimuli on motor activation: behavioral and electrophysiological evidence.
Journal of Experimental Psychology: Human Perception and Performance, 24, 1737-1747.

Eimer, M., \& Schlaghecken, F. (2002). Links between conscious awareness and response inhibition: Evidence from masked priming. Psychonomic Bulletin \& Review, 9, 514-520.

Eimer, M., \& Schlaghecken, F. (2003). Response facilitation and inhibition in subliminal priming. Biological Psychology, 64, 7-26.

Erdfelder, E., Faul, F., \& Buchner, A. (1996). GPOWER: A general power analysis program. Behavior Research Methods, Instruments, \& Computers, 28, 1-11.

Farroni, T., Massaccesi, S., Pividori, D., Simion, F., \& Johnson, M. H. (2004). Gaze following in newborns. Infancy, 5, 39-60.

Friesen, C. K., \& Kingstone, A. (1998). The eyes have it! Reflexive orienting is triggered by nonpredictive gaze. Psychonomic Bulletin \& Review, 5, 490-495.

Frischen, A., Bayliss, A. P., \& Tipper, S. P. (2007). Gaze cueing of attention: Visual attention, social cognition, and individual differences. Psychological Bulletin, 133, 694-724.

Gibson, J. J. (1979). The ecological approach to visual perception. Boston, MA: Houghton Mifflin.

Grèzes, J., Fonlupt, P., Bertenthal, B., Delon-Martin, C., Segebarth, C., \& Decety, J. (2001). Does perception of biological motion rely on specific brain regions? Neurolmage, 13, 775-785.

Grossman, E. D., \& Blake, R. (2002). Brain areas active during visual perception of biological motion. Neuron, 35, 1167-1175.

Grossman, E. D., Donelly, M., Price, R., Pickens, D., Morgan, V., Neighbor, G., \& Blake, R. (2000). Brain areas involved in perception of biological motion. Journal of Cognitive Neuroscience, 12, $711-720$

Hirai, M., Saunders, D. R., \& Troje, N. F. (2011). Allocation of attention to biological motion: Local motion dominates global shape. Journal of Vision, 11, 4.

Hommel, B., Müsseler, J., Aschersleben, G., \& Prinz, W. (2001). The theory of event coding (TEC): A framework for perception and action planning. Behavioral and Brain Sciences, 24, 849-937.

James, W. (1890). Principles of psychology. New York, NY: Holt.

Jaśkowski, P., Bialunska, A., Tomanek, M., \& Verleger, R. (2008). Maskand distractor-triggered inhibitory processes in the priming of motor responses: An EEG-study. Psychophysiology, 45, 70-85.

Jeannerod, M. (1994). The representing brain: Neural correlates of motor intention and imagery. Behavioral Brain Sciences, 17, 187-202.

Johansson, G. (1973). Visual perception of biological motion and a model for its analysis. Perception \& Psychophysics, 14, 201-211.

Johansson, G. (1976). Spatio-temporal differentiation and integration in visual motion perception. Psychological Research, 38, 379-393.

Jokisch, D., \& Troje, N. F. (2003). Biological motion as a cue for the perception of size. Journal of Vision, 3, 252-264.

Kilner, J. M., Paulignan, Y., \& Blakemore, S. J. (2003). An interference effect of observed biological movement on action. Current Biology, $13,522-525$

Klauer, K. C., \& Dittrich, K. (2010). From sunshine to double arrows: An evaluation window account of negative compatibility effects. Journal of Experimental Psychology: General, 139, 490-519.

Kourtzi, Z., \& Shiffrar, M. (1999). Dynamic representations of human body movement. Perception, 28, 49-62.

Kozlowski, L. T., \& Cutting, J. E. (1977). Recognizing the sex of a walker from a dynamic point-light display. Perception \& Psychophysics, 21, 575-580.

Kuhlmeier, V. A., Troje, N. F., \& Lee, V. (2010). Young infants detect the direction of biological motion in point-light displays. Infancy, 15, 83-93.

Leibowitz, H. (1955). Effect of reference lines on the discrimination of movement. Journal of the Optical Society of America, 45, 829-830.

Lleras, A., \& Enns, J. T. (2005). Updating a cautionary tale of masked priming: Reply to Klapp (2005). Journal of Experimental Psychology: General, 134, 436-440. 
Mather, G., Radford, K., \& West, S. (1992). Low-level visual processing of biological motion. Proceedings of the Royal Society of London B, 249, 149-155.

Mattler, U., \& Fendrich, R. (2007). Priming by motion too rapid to be consciously seen. Perception \& Psychophysics, 69, 1389-1398.

Neri, P., Morrone, M. C., \& Burr, D. C. (1998). Seeing biological motion. Nature, 395, 894-896.

O’Craven, K. M., Rosen, B. R., Kwong, K. K., Treisman, A., \& Savoy, R. L. (1997). Voluntary attention modulates fMRI activity in human MT-MST. Neuron, 18, 591-598.

Prinz, W. (1997). Perception and action planning. European Journal of Cognitive Psychology, 9, 129-154.

Puce, A., Allison, T., Bentin, S., Gore, J. C., \& McCarthy, G. (1998). Temporal cortex activation in humans viewing eye and mouth movements. Journal of Neuroscience, 18, 2188-2199.

Rizzolatti, G., Fadiga, L., Matelli, M., Bettinardi, V., Paulesu, E., Perani, D., \& Fazio, F. (1996). Localization of grasp representations in humans by PET: 1. Observation versus execution. Experimental Brain Research, 111, 246-252.

Sarkheil, P., Vuong, Q. C., Bülthoff, H. H., \& Noppeney, U. (2008). The integration of higher order form and motion by the human brain. NeuroImage, 42, 1529-1536.

Saygin, A. P., Wilson, S. M., Hagler, D. J., Bates, E., \& Sereno, M. I. (2004). Point-light biological motion perception activates human premotor cortex. The Journal of Neuroscience, 24, 6181-6188.

Schlaghecken, F., \& Eimer, M. (2002). Motor activation with and without inhibition: Evidence for a threshold mechanism in motor control. Perception \& Psychophysics, 64, 148-162.

Schmidt, F., Haberkamp, A., \& Schmidt, T. (2011). Dos and don'ts in response priming research. Advances in Cognitive Psychology, 7, $120-131$.

Shi, J., Weng, X., He, S., \& Jiang, Y. (2010). Biological motion cues trigger reflexive attentional orienting. Cognition, 117, 348-354.

Simion, F., Regolin, L., \& Bulf, H. (2008). A predisposition for biological motion in the newborn baby. Proceedings of the National Academy of Sciences, 105, 809-813.

Stürmer, B., Aschersleben, G., \& Prinz, W. (2000). Correspondence effects with manual gestures and postures: A study of imitation. Journal of Experimental Psychology: Human Perception and Performance, 26, 1746-1759.

Thornton, I. M., \& Vuong, Q. C. (2004). Incidental processing of biological motion. Current Biology, 14, 1084-1089.

Thurman, S. M., \& Grossman, E. D. (2008). Temporal "bubbles" reveal key features in point-light biological motion perception. Journal of Vision, 8(3), 1-11.
Thurman, S. M., \& Lu, H. (2013). Physical and biological constraints govern perceived animacy of scrambled human forms. Psychological Science, 24, 1133-1141.

Treue, S., \& Maunsell, J. H. R. (1996). Attentional modulation of visual motion processing in cortical areas MT and MST. Nature, 382, 539541.

Troje, N. F. (2008). Biological motion perception. In A. I. Basbaum, M. C. Bushnell, D. V. Smith, G. K. Beauchamp, S. J. Firestein, P. Dallos, D. Oertel, R. H. Masland, T. D. Albright, J. H. Kaas, \& E. P. Gardner (Eds.), The senses: a comprehensive references (Vol. 2, pp. 231-238). New York: Academic.

Troje, N. F. (2013). What is biological motion? Definition, stimuli and paradigms. In M. D. Rutherford, M. D., \& V. A. Kuhlmeier (Eds.), Social perception: Detection and interpretation of animacy, agency, and intention (pp. 13-36). MIT Press.

Troje, N. F., \& Aust, U. (2013). What do you mean with 'direction'?: Local and global cues to biological motion perception in pigeons. Vision Research, 79, 47-55.

Troje, N. F., \& Westhoff, C. (2006). Inversion effect in biological motion perception: Evidence for a 'life detector'? Current Biology, 16, 821824.

Tukey, J. W. (1977). Exploratory data analysis. Reading, MA: AddisonWesley.

Vaina, L. M., Solomon, J., Chowdhury, S., Sinha, P., \& Belliveau, J. W. (2001). Functional neuroanatomy of biological motion perception in humans. PNAS, 98, 11656-11661.

van der Wel, R. P. R. D., Sebanz, N., \& Knoblich, G. (2013). Action perception from a common coding perspective. In K. L. Johnson \& M. Shiffrar (Eds.), People watching: Social, perceptual, and neurophysiological studies of body perception (pp. 101-118). Oxford: University Press.

Vanrie, J., \& Verfaillie, K. (2004). Perception of biological motion: A stimulus set of human point-light actions. Behavior Research Methods, Instruments, \& Computers, 36, 625-629.

Verfaillie, K. (2000). Perceiving human locomotion: Priming effects in direction discrimination. Brain and Cognition, 44, 192-213.

Wang, L., Yang, X., Shi, J., \& Jiang, Y. (2014). The feet have it: Local biological motion cues trigger reflexive attentional orienting in the brain. NeuroImage, 84, 217-224.

Warren, W. H. (2006). The dynamics of perception and action. Psychological Review, 113, 358-389.

Watanabe, K. (2008). Behavioral speed contagion: Automatic modulation of movement timing by observation of body movements. Cognition, 106, 1514-1524.

Winkielman, P., McIntosh, D. N., \& Oberman, L. (2009). Embodied and disembodied emotion processing: Learning from and about typical and autistic individuals. Emotion Review, 1, 178-190. 